NBER WORKING PAPER SERIES

\title{
AN EVALUATION OF MULTI-FACTOR CIR MODELS USING LIBOR, SWAP RATES, AND CAP AND SWAPTION PRICES
}

\author{
Ravi Jagannathan \\ Andrew Kaplin \\ Steve Guoqiang Sun \\ Working Paper 8682 \\ http://www.nber.org/papers/w8682 \\ NATIONAL BUREAU OF ECONOMIC RESEARCH \\ 1050 Massachusetts Avenue \\ Cambridge, MA 02138 \\ December 2001
}

Earlier versions of the paper had Jagannathan and Sun as the authors. We thank Pat Hess and Jack Kareken for helpful discussions, Fannie Mae and University Capital Strategies Group for providing the data. We thank Jefferson Duarte, Michael Johannes, Nour Meddahi, Krishna Ramaswamy and Robert Stambaugh, anonymous referee, and seminar and conference participants at the Universities of California/Berkeley, Chicago and Pennsylvania, Federal Reserve Bank of New York, McGill University, and Duke University for helpful comments. All errors are our own. The views expressed herein are those of the authors and not necessarily those of the National Bureau of Economic Research.

(C) 2001 by Ravi Jagannathan, Andrew Kaplin and Steve Guoqiang Sun. All rights reserved. Short sections of text, not to exceed two paragraphs, may be quoted without explicit permission provided that full credit, including $(\mathcal{C}$ notice, is given to the source. 
An Evaluation of Multi-Factor CIR Models Using LIBOR, Swap Rates, and Cap and Swaption Prices

Ravi Jagannathan, Andrew Kaplin and Steve Guoqiang Sun

NBER Working Paper No. 8682

December 2001

JEL No. C13, C32, C51, E43, G12

\begin{abstract}
We evaluate the classical Cox, Ingersoll and Ross (1985) (CIR) model using data on LIBOR, swap rates and caps and swaptions. With three factors the CIR model is able to fit the term structure of LIBOR and swap rates rather well. The model is able to match the hump shaped unconditional term structure of volatility in the LIBOR-swap market. However, statistical tests indicate that the model is misspecified. In particular the pricing errors are related to the slope of the swap yield curve. The economic importance of these shortcomings is highlighted when the model is confronted with data on cap and swaption prices. Pricing errors are large relative to the bid-ask spread in these markets. The model tends to overvalue shorter maturity caps and undervalue longer maturity caps. With only one or two factors, the model also tends to undervalue swaptions. Our findings point out the need for evaluating term structure models using data on derivative prices.
\end{abstract}

Ravi Jagannathan

J.L. Kellogg Graduate School of Management

Northwestern University

2001 Sheridan Road

Leverone/Anderson Complex

Evanston, IL 60208-2001

and NBER

rjaganna@nwu.edu

Andrew Kaplin

Northwestern University

a-kaplin@nwu.edu

Steve Guoqiang Sun

University Capital Strategies Group 


\section{Introduction}

The last two decades have seen an explosive growth in the use of interest rate derivatives by institutions. A number of theoretical term structure models have been proposed in the literature for understanding the risk in such derivative products and for valuing them. However, there have been only a few published empirical studies of these valuation models using data on derivative prices. This lack of empirical work has impeded the full development of practical tools based on these models. We fill this void in the empirical term structure literature.

In particular, we empirically examine the classical three-factor Cox, Ingersoll Ross (1985) (CIR) model using data on LIBOR and swap rates. Unlike Grinblatt who separately identifies the credit spread, we use the framework developed by Duffie and Singleton (1999) and directly model the default-adjusted yield without separating the credit spread component. The advantage of this approach is that under mild technical regularity conditions, (see Duffie and Singleton (1997), 696-697) existing term structure models for Treasury bonds can be used to model the LIBOR yield curve, with the riskfree rate replaced by the default-adjusted rate.

Although the CIR model has received wide attention in the theoretical literature, its empirical performance has not yet been evaluated using price data on interest rate derivative claims. We find that with three factors, the CIR model fits the term structure of LIBOR and swap rates well. The model pricing errors are reasonable given the bid-ask spread in these markets. However when evaluated using price data on caps and swaptions, the model is not satisfactory. These findings are similar to those reported in Longstaff, Santa-Clara and Schwartz (2000) for stochastic string models and stress the need to use derivative price data (along with data on interest rates) to evaluate the economic importance of the statistical rejections of theoretical models.

\section{Related Literature}

Pearson and Sun (1994) evaluate the empirical performance of the two-factor version of the CIR model and an extension that nests the two-factor specification using interest rate data. They examine the accuracy of the models' forecasts of future interest rates against that obtained using a "naive" rule. They find that the "naive" rule performs better than the two-factor model as well as its extension. Chen and Scott (1993) use the model-pricing-errors for bonds of different maturities to compare the relative performance of two-factor and three-factor CIR models. They find that the two-factor model performs almost as well as the three-factor model. Jegadeesh and Pennacchi (1996) empirically examine a two-factor Gaussian term structure model. They find that while the two-factor model shows a significant improvement over the one factor models examined in the literature the model has difficulty capturing the term structure of volatility in the Eurodollar futures market. Duffie and Singleton (1997) find a two-factor model to be inadequate in fitting the term structure of swap yields. Das and Foresi (1996), Johannes (1999) and Piazzezi (1999) suggest augmenting the models with jump components. Chacko and Das (2000) provide pricing formulae for a variety of derivative claims for models in the affine class that may also include jump components. Dai and Singleton (1999) provide a comprehensive evaluation of different term structure models 
within the affine class and find that some sub families within the affine class have better potential than others. However, they do not use derivative prices in their otherwise extensive study.

There is substantial empirical evidence documenting the shortcomings of affine term structure models of which multifactor CIR models form a part. Backus, Foresi, Mozumdar and $\mathrm{Wu}$ (1998) demonstrate that term premiums generated by affine models may be too low when compared with what we observe in the data. Using semi nonparametric statistical methods, Ghysels and $\mathrm{Ng}$ (1998) find evidence against affine models. Duffee (2000) points out that affine term structure models are not flexible enough to produce the observed temporal patterns in interest rate volatilities and produce poor forecasts of future changes in interest rates. In view of this Duffee (2000) and Duarte (2000) propose extending the classical affine class of models to allow for more flexible parameterization of the market price of risk. Bansal and Zhou (2000) propose a model that allows for regime shifts.

Although these studies document the shortcomings of affine term structure models along interesting dimensions, none of them examine whether these shortcomings are sufficiently severe to affect their use in valuing interest rate derivative claims. We show that this is indeed the case for multifactor CIR models. We estimate the model parameters using time series data on LIBOR and swap rates, following the maximum likelihood method described in Pearson and Sun (1994). We assume that one LIBOR or swap rate is observed without error while estimating the one-factor model and that other LIBOR and swap rates are measured with error. For the two-factor model, we assume two LIBOR and swap rates are observed without error, and similarly for the three-factor model. In each case, the log-likelihood is the sum of that from the exactly matched rates and that from the measurement error. Using the estimated model parameters, we predict the future LIBOR and swap rates and compare them with the realized values. We also compute the pricing errors for CAPS and swaptions. Larger pricing errors would show a greater model misspecification.

We organize the rest of the paper as follows. Section 2 applies multifactor CIR models to the LIBOR and swap markets. Section 3 contains the estimation results using LIBOR and swap rates. Section 4 applies CIR models to price CAPS and swaptions. Section 5 concludes.

\section{Multifactor CIR Models for the LIBOR Yield Curve}

\section{A. Valuation of bonds that are subject to default risk}

Under the assumption that no arbitrage opportunities exist, the value process of a contingent claim discounted at the risk-free interest rate is a martingale under some equivalent martingale measure $Q$. Specifically, let $P_{t}$ and $r_{t}$ be respectively the value of the contingent claim and the instantaneous risk-free interest rate at date $t$. Then

$$
P_{t}=E_{t}^{Q}\left[\exp \left(-\int_{t}^{T} r_{s} d s\right) P_{T}\right] .
$$


This formula can be used to price any claim where we know the timing of the final payoff. When the security is subject to default risk, (2.1) cannot be used directly. Here the final payoff $\mathrm{P}_{\mathrm{T}}$ and the time of the final payoff $\mathrm{T}$ are uncertain, since default can occur anytime.

Duffie and Singleton (1999) show, however, that if we replace the risk-free rate in (2.1) with a default-adjusted rate, it can still be used to price the risky claim, with $\mathrm{P}_{\mathrm{T}}$ being the promised payoff at the specified expiration date T, i.e.,

$$
P_{t}=E_{t}^{Q}\left[\exp \left(-\int_{t}^{T} R_{s} d s\right) P_{T}\right]
$$

We identify the equivalent martingale measure, $\mathrm{Q}$, and relate it to the parameters of the stochastic process determining the temporal evolution of the interest rates in the following way.

Following Duffie and Singleton (1997), we assume that there are $n$ independent state variables, each evolving over time according to a square root process

$$
d y_{i t}=\kappa_{i}\left(\theta_{i}-y_{i t}\right) d t+\sigma_{i} \sqrt{y_{i t}} d W_{i}(t), \quad i=1,2, \ldots, n .
$$

where $W_{i}$ 's are independent Brownian motions. The market price of risk, $\lambda_{i}$ for each state variable, $\mathrm{y}_{\mathrm{i}}$, is assumed to be linear. Using arguments similar to those in Cox, Ingersoll and Ross (1985), it can be shown that under the equivalent martingale measure,

$$
d y_{i t}=\bar{k}_{i}\left(\bar{\theta}_{i}-y_{i t}\right) d t+\sigma_{i} \sqrt{y_{i t}} d W_{i t}^{*}
$$

where $\bar{k}_{i}$ and $\bar{\theta}_{i}$ is given by,

$$
\bar{k}_{i}=k_{i}+\lambda_{i}, \bar{\theta}_{i}=\frac{k_{i} \theta_{i}}{k_{i}+\lambda_{i}} .
$$

The instantaneous default-adjusted rate is assumed to be the sum of all state variables

$$
R_{t}=\sum_{i=1}^{n} y_{i t} .
$$

Prices of pure discount bonds can be derived following Cox, Ingersoll, and Ross (1985). By using Girsanov's theorem (see Sun (1998)) the fundamental pricing equation (2.2) can be transformed to an expectation under another measure, under which the state still follows a square root process. However the integral instead of being over a path, involves only the terminal value $R_{T}$. Namely, there exists an equivalent measure $\mathrm{H}$ such that (2.2) can be rewritten as

$$
V_{t}=\pi_{t} E_{t}^{H}\left[\exp \left(\sum_{i=1}^{n} \frac{\gamma_{i}-\bar{k}_{i}}{\sigma_{i}^{2}} y_{i T}\right) X\right]
$$

where

$$
\begin{aligned}
& \pi_{t}=\exp \left[-\sum_{i=1}^{n}\left(\frac{\gamma_{i}-\bar{k}_{i}}{\sigma_{i}^{2}} y_{i t}-\frac{k_{i} \theta_{i}\left(\gamma_{i}-\bar{k}_{i}\right)}{\sigma_{i}^{2}}(T-t)\right)\right] \\
& \gamma_{i}=\sqrt{\bar{k}_{i}^{2}+2 \sigma_{i}^{2}}
\end{aligned}
$$


Under measure $\mathrm{H}$, the process $y_{i}$ follows

$$
d y_{i t}=\left(k_{i} \theta_{i}-\gamma_{i} y_{i t}\right) d t+\sigma_{i} \sqrt{y_{i t}} d \hat{W}_{t}
$$

The defaultable discount bond price is then given by ${ }^{1}$

$$
P(t, T)=\prod_{i=1}^{n} p_{i}(t, T),
$$

where $p_{i}(t, T)=A_{i}(t, T) e^{-B_{i}(t, T) y_{i t}}$, for

$$
\begin{aligned}
& A_{i}(t, T)=\left[\frac{2 \gamma_{i} \exp \left[\left(\gamma_{i}+\bar{k}_{i}\right)(T-t) / 2\right]}{\left(\gamma_{i}+\bar{k}_{i}\right)\left[\exp \left(\gamma_{i}(T-t)\right)-1\right]+2 \gamma_{i}}\right]^{2 k_{i} \theta_{i} / \sigma_{i}^{2}}, \\
& B_{i}(t, T)=\frac{2\left[\exp \left(\gamma_{i}(T-t)\right)-1\right]}{\left(\gamma_{i}+\bar{k}_{i}\right)\left[\exp \left(\gamma_{i}(T-t)\right)-1\right]+2 \gamma_{i}} .
\end{aligned}
$$

The yield to maturity is a sum of that from each state

$$
\operatorname{YTM}(\tau)=\sum_{i=1}^{n} \operatorname{YTM}_{i}(\tau),
$$

where $Y T M_{i}(\tau)$ is linear in $y_{i t}$ but nonlinear in $\tau$. The limiting cases are

$$
\begin{aligned}
& \operatorname{YTM}_{i}(0)=y_{i t} \\
& \operatorname{YTM}_{i}(\infty)=\frac{2 k_{i} \theta_{i}}{\gamma_{i}+\bar{k}_{i}} .
\end{aligned}
$$

If $\bar{k}_{i}>0$, it can be shown that when $y_{i t}<Y T M_{i}(\infty), Y T M_{i}(\tau)$ is an increasing function of $\tau$; when $y_{i t}>\bar{\theta}_{i}$, it is a decreasing function; and for intermediate values, the function is humped. If $\bar{k}_{i}<0, Y T M_{i}(\tau)$ is an increasing function of $\tau$ initially, no matter what value the current state takes. Then it will continue to increase or start to decrease, depending on the relationship between the spot state and the long-term yield. Finally, the long-term yield is a decreasing and convex function of the market price of risk. A negative market price of risk implies a positive term premium.

The yield curve in the multifactor model can be rising, falling or humped. Depending on the current realizations of the state variables, it can even have an inversehump, which the one-factor model does not admit.

One of the properties of CIR specification is that the volatility of the short rate diminishes as the level of it approaches zero. To enable the model to have sufficiently high volatility at low levels we add a negative constant to (2.6). Here the default-adjusted rate, $\mathrm{R}_{\mathrm{t}}$, and the discount bond price, $\mathrm{P}(\mathrm{t}, \mathrm{T})$, are modified as follows:

$$
\begin{aligned}
& R_{t}=\sum_{i=1}^{n} y_{i t}+\bar{y} \\
& P(t, T)=\prod_{i=1}^{n} p_{i}(t, T) e^{-\bar{y}(T-t)}
\end{aligned}
$$

${ }^{1}$ See Sun (1998) for a derivation of the bond pricing formulae, following Cox, Ingersoll, and Ross (1985). 
respectively, where $p_{i}(t, T)$ is the same as in equation (2.11). The case (2.6) can be considered a special case of (2.17) where $\bar{y}=0$.

\section{B. LIBOR and Swap Rates}

The London Interbank Offer Rate (LIBOR) rates are generally higher than the corresponding Treasury bill interest rates since they are subject to the default risk of the participating banks. Given the price of a zero-coupon defaultable bond, we can compute LIBOR rates. Let $P(t, T)$ be the price at date $t$ of a defaultable discount bond with maturity date $T$, and $R_{\tau}$ be the LIBOR rate with a term to maturity $\tau$. Then by definition,

$$
R_{\tau}=\frac{1}{\tau}\left(\frac{1}{P(t, t+\tau)}-1\right)
$$

In a common "plain vanilla" interest rate swap, party B agrees to pay to party A cash flows equal to interest at a predetermined fixed rate on notional principal for some number of years. At the same time, party A agrees to pay party B cash flows equal to interest at a floating rate on the same notional principal for the same period. The floating rate in the swap is set at the beginning of each period and paid at the end of the period. The floating rate in many interest rate swap agreements is the LIBOR rate. The life of the swap can range from two years to more than 15 years. By convention, a swap contract has a value of zero at the inception date. Since the floating side has a par value, the fixed side is a par coupon bond, and the coupon rate is the prevailing swap rate.

To find a fair swap rate, it is necessary to discount the cash flows in a swap at LIBOR rates. The implicit assumption is that the risk associated with swap cash flows is the same as the risk associated with the cash flows on a loan in the interbank market. Assuming a 6-month settlement period, we have

$$
c=2 \times \frac{1-P(t, T)}{\sum_{i=1}^{n} P(t, t+i / 2)}
$$

where $c$ is the prevailing swap rate and $P$ the price of the same discount bonds that were used in (2.19) to determine LIBOR rates.

In a CIR model, both LIBOR and swap rates are determined by state variables through the prices of discount bonds. These are all non-linear functions of the state variables.

\section{Interest Rate Caps}

The interest rate caps that we examine are written on LIBOR with payments made at the end of each period. In general, a cap is characterized by the cap rate $R_{X}$, the settlement period $\tau$, and maturity T. Suppose interest payments are made at times $\tau, 2 \tau, \ldots$, $\mathrm{n} \tau=\mathrm{T}$ from the beginning of the life of the cap and the notional amount of the contract is $\$ 1$. Then the holder's payoff at time $(i+1) \tau$ is 


$$
\tau \max \left(R_{i}-R_{X}, 0\right)
$$

where $R_{i}$ is the value at time $i \tau$ of the rate being capped. This call option on the rate being capped is commonly referred to as a caplet. A cap is a portfolio of caplets. The common practice in the financial markets is to price a caplet using Black's (1976) model (see Hull (1997)). To price a cap written on LIBOR, this model assumes a log-normal process for the LIBOR rate.

The value at time $i \tau$ of the payoff from the caplet that occurs at time $(i+1) \tau$ given in (2.21) is

$$
\frac{\tau}{1+R_{i}} \max \left(R_{i}-R_{X}, 0\right)=\left(1+R_{X}\right) \max \left(\frac{1}{1+R_{X}}-\frac{1}{1+R_{i}}, 0\right),
$$

which is $\left(1+R_{X}\right)$ times the payoff on a put option on a $\$ 1$ par zero-coupon bond with strike price $1 /\left(1+\tau R_{X}\right)$. Therefore, a cap can also be considered a portfolio of put options on zero-coupon bonds.

In a CIR model, an analytical expression for options on zero-coupon bonds is available. We therefore use the second interpretation, a portfolio of put options on zerocoupon bonds, to compute the cap price.

We first compute the price of a put option on a discount bond. The integration region in (2.7) is now given by $P(T, s) \leq K$ where $\mathrm{P}(\mathrm{T}, \mathrm{s})$ is the discount bond price. This generates a linear boundary

$$
\sum_{i=1}^{n} y_{i T} / y_{i}^{*} \geq 1
$$

where

$$
y_{i}^{*}=\left(-\bar{y}(s-T)+\ln \left(\prod_{i=1}^{n} A_{i} / K\right)\right) / B_{i}
$$

and $A_{i}$ and $B_{i}$ are defined by (2.12) and (2.13). The price of a put option on a discount bond is given by (see Chen and Scott (1992) and Sun (1998)):

$$
\begin{aligned}
P^{p u t}(t, T, s, K) & =K P(t, T)\left(1-\chi^{2}\left[L_{1}, \ldots, L_{n} ; v_{1}, \ldots, v_{n}, \delta_{1}, \ldots, \delta_{n}\right]\right) \\
& -P(t, s)\left(1-\chi^{2}\left[L_{1}{ }^{*}, \ldots, L_{n}{ }^{*} ; v_{1}, \ldots, v_{n}, \delta_{1}{ }^{*}, \ldots, \delta_{n}{ }^{*}\right]\right)
\end{aligned}
$$

where

$$
\begin{aligned}
& L_{i}=2 \psi_{i} y_{i}^{*}, L_{i}^{*}=2 \psi_{i}^{*} y_{i}^{*} \\
& \delta_{i}=y_{i t} \phi_{i}^{2} \exp \left[\gamma_{i}(T-t)\right] / \psi_{i}, \quad \delta_{i}^{*}=y_{i t} \phi_{i}^{2} \exp \left[\gamma_{i}(T-t)\right] / \psi_{i}^{*} \\
& \psi_{i}=2\left(\phi_{i}+\frac{\gamma_{i}+\bar{k}_{i}}{\sigma_{i}^{2}}\right), \quad \psi_{i}^{*}=2\left(\phi_{i}+\frac{\gamma_{i}+\bar{k}_{i}}{\sigma_{i}^{2}}+B_{i}(T, s)\right) \\
& \phi_{i}=\frac{2 \gamma_{i}}{\sigma_{i}^{2}\left(\exp \left[\gamma_{i}(T-t)\right]-1\right)}, \quad v_{i}=4 k_{i} \theta_{i} / \sigma_{i}^{2}
\end{aligned}
$$

The $\chi^{2}$ is the multidimensional cumulative noncentral chi-square distribution function. The two and three-dimensional cases are given by 


$$
\begin{aligned}
& \chi^{2}\left[L_{1}, L_{2} ; v_{1}, v_{2}, \delta_{1}, \delta_{2}\right]=\int_{0}^{L_{2}} F\left(L_{1}\left(1-\frac{x_{2}}{L_{2}}\right) ; v_{1}, \delta_{1}\right) f\left(x_{2} ; v_{2}, \delta_{2}\right) d x_{2} \\
& \chi^{2}\left[L_{1}, L_{2}, L_{3} ; v_{1}, v_{2}, v_{3}, \delta_{1}, \delta_{2}, \delta_{3}\right] \\
& =\int_{0}^{L_{3}} f\left(x_{3} ; v_{3}, \delta_{3}\right) d x_{3} \int_{0}^{L_{2}\left(1-x_{3} / L_{3}\right)} F\left(L_{1}\left(1-\frac{x_{2}}{L_{2}}-\frac{x_{3}}{L_{3}}\right) ; v_{1}, \delta_{1}\right) f\left(x_{2} ; v_{2}, \delta_{2}\right) d x_{2}
\end{aligned}
$$

where $F$ and $f$ are the probability and density functions respectively of a univariate noncentral chi-square distribution.

The cap is then the summation of the individual caplets, where each is a put option on a discount bond whose price is given by (2.22). An $N$-period cap will have $N-1$ caplets, since there is no need to cap the first payment.

\section{Interest Rate Swaptions}

An interest rate swaption is an option on interest rate swaps. It gives the holder the right to enter into a specific interest rate swap at a specific time in the future. A payertype swaption gives the holder the right to pay the fixed interest rate payments and receive the floating. A receiver-type swaption gives the holder the right to receive the fixed rate payment and pay the floating. The receiver swaption is a portfolio of put options on future swap rates, each with an identical strike rate (which is the swap rate specified in the swaption contract), and an identical reference rate (which is the future swap rate). In the other case, a payer swaption is a call option. We now focus on the receiver-type option.

The common practice in the financial markets is to price a swaption using Black's (1976) model (see Hull (1997)). To price a swaption, this model assumes a log-normal process for the swap rate.

An interest rate swaption can be regarded as an agreement to exchange a fixedrate bond for a floating-rate bond. Since the floating-rate bond is worth par at the start of the swap, a receiver swaption can be regarded as a call option on a coupon bond, with the strike price equal to par and the coupon rate being the future swap rate. In the CIR framework, we use this interpretation to price swaptions.

The price computation for a call option on a coupon bond is more complicated than that for a call option on a discount bond, since we now have a nonlinear, nonclosed form boundary. Consider a coupon bond ( $\$ 1$ par) with first coupon date $T$, maturity $s$, coupon rate $c$ and settlement period $\tau$. The price of this bond at date $t$ is given by

$$
P(t, T, s, \tau, c)=\sum_{j=0}^{n-1} c_{j} P(t, T+j \tau), \quad n=(s-T) / \tau+1
$$

where

$$
c_{j}=\tau c \text { for } j \neq n-1, \quad c_{n-1}=1+\tau c .
$$

Now consider a European call option on this coupon bond, with an exercise price K. The integration region in (2.7) is given by 


$$
P(T, T+\tau, s, \tau, c) \leq K .
$$

We must solve (2.34) numerically to obtain the critical values of the state variables. Since the discount bond price is a decreasing function of the state variables, the coupon bond price is also a decreasing function of the state variables. The critical values thus formed a curve for the integration. Let $y_{i}{ }^{*}\left(y_{i_{1}}, \ldots, y_{i_{k}}\right)$ be the value of $y_{i}$ such that $P(T, T+\tau, s, \tau, c)=K$ for given values of $y_{i_{1}}, \ldots, y_{i_{k}}$ and zero values of all other y's that do not appear in the argument list. Therefore $y_{i}^{*}()$ is the value of $y_{i}$ such that $P(T, T+\tau, s, \tau, c)=K$ when all other state variables are zero.

The price of a call option on a coupon bond is given (see Chen and Scott (1995) and Sun (1998)) by

$$
\begin{aligned}
P^{\text {call }}(t, T, s, \tau, c, K)= & P(t, T, s, \tau, c) \sum_{i=1}^{n} w_{j} \chi^{2}\left[X_{1 j}^{*}, \ldots, X_{n j}^{*} ; v_{1}, \ldots, v_{n}, \delta_{1 j}^{*}, \ldots, \delta_{n j}^{*}\right] \\
& -K P(t, T) \chi^{2}\left[X_{1}, \ldots, X_{n} ; v_{1}, \ldots, v_{n}, \delta_{1}, \ldots, \delta_{n}\right]
\end{aligned}
$$

where

$$
\begin{aligned}
& w_{j}=\frac{c_{j} P(t, T+j \tau)}{P(t, T, s, \tau, c)}, \\
& X_{1}=\psi_{1} y_{1}^{*}\left(\frac{x_{2}}{\psi_{2}}, \ldots, \frac{x_{n}}{\psi_{n}}\right), X_{2}=\psi_{2} y_{2}^{*}\left(\frac{x_{3}}{\psi_{3}}, \ldots, \frac{x_{n}}{\psi_{n}}\right), \ldots, X_{n}=\psi_{n} y_{n}^{*}() . \\
& X_{1 j}^{*}=\psi_{1 j}^{*} y_{1}^{*}\left(\frac{x_{2}}{\psi_{1 j}^{*}}, \ldots, \frac{x_{n}}{\psi_{n j}^{*}}\right), X_{2 j}^{*}=\psi_{2 j}^{*} y_{2}^{*}\left(\frac{x_{3}}{\psi_{3 j}^{*}}, \ldots, \frac{x_{n}}{\psi_{n j}^{*}}\right), \ldots, X_{n j}^{*}=\psi_{n j}^{*} y_{n}^{*}() . \\
& \psi_{i j}^{*}=\phi_{i}+\frac{\gamma_{i}+\bar{k}_{i}}{\sigma_{i}^{2}}+B_{i}(T, T+j \tau), \delta_{i j}^{*}=2 y_{i t} \phi_{i}^{2} \exp \left[\gamma_{i}(T-t)\right] / \psi_{i j}^{*} .
\end{aligned}
$$

All other variables are the same as in (2.27)-(2.29).

The two and three-dimensional cumulative noncentral chi-square distributions are respectively

$$
\begin{aligned}
& \chi^{2}\left[X_{1}, X_{2} ; v_{1}, v_{2}, \delta_{1}, \delta_{2}\right]=\int_{0}^{X_{2}} F\left(X_{1} ; v_{1}, \delta_{1}\right) f\left(x_{2} ; v_{2}, \delta_{2}\right) d x_{2} \\
& \begin{array}{l}
\chi^{2}\left[X_{1}, X_{2}, X_{3} ; v_{1}, v_{2}, v_{3}, \delta_{1}, \delta_{2}, \delta_{3}\right] \\
\quad=\int_{0}^{X_{3}} f\left(x_{3} ; v_{3}, \delta_{3}\right) d x_{3} \int_{0}^{X_{2}} F\left(X_{1} ; v_{1}, \delta_{1}\right) f\left(x_{2} ; v_{2}, \delta_{2}\right) d x_{2}
\end{array}
\end{aligned}
$$

\section{E. Computation of the Multidimensional Distribution using Fourier Inversion}

The multidimensional integral of the noncentral chi-square distribution in cap and swaption price is computationally demanding. Chen and Scott (1995) proposed an alternative approach to compute the multidimensional distribution. It is based on Fourier inversion and is much faster when the integral boundary is linear. 
The central idea is the relationship between distribution function $F(x)$ and the characteristic function $\Phi(t)$ (see Shephard (1991))

$$
F(x)=\frac{1}{2}-\frac{1}{\pi} \int_{0}^{\infty} \operatorname{imag}\left(\frac{\Phi(t) e^{-i t x}}{t}\right) d t .
$$

Therefore, the cumulative distribution can be regarded as Fourier inversion of the characteristic function. The characteristic function has a nice property that, if a random variable is a linear combination of some independent random variables, its characteristic function is simply the product of their characteristic functions. Namely,

$$
\Phi(t)=\prod_{i=1}^{n} \Phi_{i}\left(a_{i} t\right) \text { for } X=\sum_{i=1}^{n} a_{i} y_{i} .
$$

Applying these results to the multidimensional noncentral chi-square distribution in the expression for the cap price, gives:

$$
\begin{aligned}
& \chi^{2}\left[L_{1}, \ldots, L_{n} ; v_{1}, \ldots, v_{n}, \delta_{1}, \ldots, \delta_{n}\right]=\frac{1}{2}-\frac{1}{\pi} \int_{0}^{\infty} \operatorname{imag}\left(\frac{e^{-i t}}{t} \prod_{i=1}^{n} \Phi_{i}\left(\frac{t}{\psi_{i} y_{i}^{*}}\right)\right) \\
& \chi^{2}\left[L_{1}^{*}, \ldots, L_{n}^{*} ; v_{1}, \ldots, v_{n}, \delta_{1}^{*}, \ldots, \delta_{n}^{*}\right]=\frac{1}{2}-\frac{1}{\pi} \int_{0}^{\infty} \operatorname{imag}\left(\frac{e^{-i t}}{t} \prod_{i=1}^{n} \Phi_{i}^{*}\left(\frac{t}{\psi_{i}^{*} y_{i}^{*}}\right)\right)
\end{aligned}
$$

where

$$
\begin{aligned}
& \Phi_{i}(t)=(1-2 i t)^{-v_{i} / 2} \exp \left[i t \delta_{i} /(1-2 i t)\right] \\
& \Phi_{i}{ }^{*}(t)=(1-2 i t)^{-v_{i} / 2} \exp \left[i t \delta_{i}^{*} /(1-2 i t)\right]
\end{aligned}
$$

are the characteristic functions of $\chi^{2}\left[x ; v_{i}, \delta_{i}\right]$ and $\chi^{2}\left[x ; v_{i}, \delta_{i}^{*}\right]$ respectively. Since only one-dimensional integrals are involved in (2.44) and (2.45), the computation becomes much easier.

For the swaption price, the boundary is nonlinear and this approach cannot be applied directly. Chen and Scott (1995) suggest that we compute the probability under the linear boundary using Fourier inversion and those between the linear and nonlinear boundary using the multidimensional integral. The difference between these two probabilities is the probability in the swaption price. The resulting computations, however, are still time consuming for the three-factor model.

\section{Evaluating Multifactor CIR Models Using LIBOR and Swap Rates}

\section{A. Econometric Method}

Following Pearson and Sun (1994), Chen and Scott (1993), and Duffie and Singleton (1996), the joint distribution of observed LIBOR and swap rates can be obtained from the noncentral chi-square distributions of the state variables through a change of variable. We first invert the pricing equations (2.16) and (2.17) to express the 
unobservable state variables as functions of observed rates. We then apply quasimaximum likelihood estimation to obtain parameter estimates.

For this purpose, write (2.16) and (2.17) as

$$
r_{i t}=g_{i}\left(y_{1 t}, \ldots, y_{n t}\right), \quad i=1, \ldots, n ; n=1,2,3
$$

where $r_{i t}$ is either the LIBOR rate or the swap rate. Given the appropriate parameter values, the above system of nonlinear equations can be solved numerically for the state variables as functions of observed rates, i.e., $y_{i t}\left(r_{1 t}, \ldots, r_{n t}\right), i=1, \ldots, n ; n=1,2,3$. For a nfactor model, we assume that $n$ of the rates are observed without any error and invert the rates to get the $n$ state variables. For the one factor model, the inversion is unique since both LIBOR and swap rates are increasing functions of the state variable. For two- and three-factor models, we cannot guarantee the uniqueness.

Through a change of variable, the joint conditional density of the exactly observed rates can be written as

$$
f_{r}\left(r_{1 T}, \ldots, r_{n T} \mid r_{1 t}, \ldots, r_{n t}\right)=J^{-1} \prod_{i=1}^{n} f\left(y_{i T}\left(r_{1 T}, \ldots, r_{n T} \mid y_{i t}\left(r_{1 t}, \ldots, r_{n t}\right)\right)\right.
$$

where $f$ is the conditional noncentral chi-square density given by

$$
f\left(y_{i T} \mid y_{i t}\right)=2 c_{i} f\left(2 c_{i} y_{i T} ; v_{i}, \lambda_{i}\right)
$$

where

$$
\begin{aligned}
& c_{i}=\frac{2 k_{i}}{\sigma_{i}^{2}\left(1-\exp \left(-k_{i}(T-t)\right)\right)}, \\
& \lambda_{i}=2 c_{i} y_{i t} \exp \left[-k_{i}(T-t)\right] \\
& f(x ; v, \lambda)=\frac{1}{2} e^{-(x+\lambda) / 2}\left(\frac{x}{\lambda}\right)^{q / 2} I_{q}(\sqrt{\lambda x}), q=\frac{v}{2}-1
\end{aligned}
$$

is the probability density of a non-central chi-square distribution $\chi^{2}(x ; v, \lambda)$, with $v$ degrees of freedom and parameter of noncentrality $\lambda$, and $\mathrm{I}_{\mathrm{q}}($.$) is the modified Bessel$ function of order q, and $J$ is the Jacobian of the transformation

$$
J=\left|\begin{array}{ccc}
\frac{\partial g_{1}}{\partial y_{1}} & \cdots & \frac{\partial g_{1}}{\partial y_{n}} \\
\vdots & \ddots & \vdots \\
\frac{\partial g_{n}}{\partial y_{1}} & \cdots & \frac{\partial g_{n}}{\partial y_{n}}
\end{array}\right|
$$

If $g$ is the LIBOR rate in (2.15), the derivative term is given as

$$
\frac{\partial g}{\partial y_{i}}=\frac{B_{i}(t, T)}{\tau P} .
$$

If $g$ is the swap rate in (2.17), the derivative is 


$$
\frac{\partial g}{\partial y_{i}}=2 \times \frac{B_{i}(t, T) P(t, T) \sum_{j=1}^{n} P\left(t, t+\frac{j}{2}\right)+(1-P(t, T)) \sum_{j=1}^{n} B_{i}\left(t, t+\frac{j}{2}\right) P\left(t, t+\frac{j}{2}\right)}{\left(\sum_{j=1}^{n} P\left(t, t+\frac{j}{2}\right)\right)^{2}} .
$$

The log-likelihood of the exactly observed rates is

$$
\log L_{1}=\sum_{t=1}^{T-1} \ln f_{r}\left(r_{1 t+1}, \ldots, r_{n t+1} \mid r_{1 t}, \ldots, r_{n t}\right) .
$$

For a $\mathrm{n}$-factor model, only $\mathrm{n}$ observed rates are needed to identify the state variables (factors). Since we have more rates than needed to identify the factors, we follow the common practice, and assume that the other rates are observed with error. The measurement error $\delta_{i t}$ is defined as the difference between the observed and the fitted rate. We assume the errors are i.i.d. Normal with mean zero and possibly nonzero correlation. The log-likelihood for measurement errors is

$$
\log L_{2}=-\frac{m T}{2} \ln (2 \pi)-\frac{T}{2} \ln |\Omega|-\frac{1}{2} \sum_{t=2}^{T} \delta_{t}{ }^{\prime} \Omega^{-1} \delta_{t}
$$

where $\Omega$ is the covariance matrix for $\delta_{t}$. The total log-likelihood is the sum of the loglikelihoods of the exactly observed rates and the measurement errors.

\section{B. Description of the Data}

The average bid-ask spreads for the LIBOR and swap rates were obtained from Bloomberg for the period from February 3, 1995 till July 16, 1999. The LIBOR rate is for the 3-month maturity, and swap rates are for maturities of 2-, 3-, 5-, 7- and 10-years. For each rate ${ }^{2}$, the observations are weekly, and there is a total of 233 data points. To show the behavior of interest rates during this sample period, the 3-month LIBOR, 2-year swap, and 10-year swap rates are graphed in Figure 1. The rates generally decrease during the first quarter of the sample period. Then the short rate remains relatively stable till September 1998, while the long rate goes up and down during that period, reaching as high as $7.365 \%$, June of 1996 . During the last quarter the long rate goes up while the short rate takes a dive to $4.195 \%$ before going up. The 10 -year swap rate is generally higher than the 3-month LIBOR rate, but the only exception is two weeks in October of 1998. The spread varies a great deal without any observable pattern.

We report the sample means and standard deviations in Table 2, panel A. Our sample means and standard deviations of weekly changes in LIBOR and swap rates are reported in panel B. The average 3-month LIBOR rate in this period is $5.627 \%$ with standard deviation $0.322 \%$ (the 3-month LIBOR rate data set has had an anomaly substituted with an average of previous and following rates). The average 10-year swap rate is $6.513 \%$ with standard deviation $0.565 \%$, and the rates are on average upward sloping. The LIBOR rate is less volatile than the swap rate, and the short-term swap rate is less volatile than the long-term swap rate. For weekly changes, all the means are

\footnotetext{
${ }^{2}$ All rates are quoted on annual basis and in computations one week is assumed to represent 1/52 of a year.
} 
approximately $.5-.6$ basis points negative. This shows that over the past half decade interest rates have on average declined. The standard deviations range from 5.036 basis points for the 3-month LIBOR up to 10.651 basis points for the 3-year swap rate, and the volatility curve is hump shaped (see Figure 3 ).

Table 4, Panel A contains the results from principal component analysis of weekly changes of LIBOR and swap rates. Each column represents one independent factor and each row represents the weight of a particular rate in this factor. For example, the first factor (Level) consists of 0.1228 of the 3-month LIBOR rate changes, 0.4280 of the 2year swap rate changes, etc., all the way down to 0.4198 of the 10 -year swap rate changes. Since this factor has positive, almost equal weights on all rates, we generally refer to it as the level factor. The last row is the percentage of the sum of the variances of all the rate changes explained by each factor. The level factor explains $93.697 \%$ of the total variation and is the dominant factor. The second factor is mainly the difference between the LIBOR rate (weight -0.8662) and swap rates (with larger weight put on longer rates). It is therefore generally called the slope factor. It explains $3.554 \%$ of the total variation. The third factor has positive weights on short-end LIBOR (0.4817) and long-end 7- and 10year swap rates (total weights 0.7986 ), but negative weights on intermediate 2-, 3-, and 5year swap rates (total weights -0.9424). It is generally named the curvature factor. It explains $1.961 \%$ of the total variation. These three independent factors explain more than $99 \%$ of the total variation in rates. We therefore conclude that three independent factors drive the term structure of LIBOR and swap rates: level, slope and curvature.

Table 3, Panel B reports the R-square values from the regression of weekly changes in the 3-month LIBOR, and 2- and 10-year swap rates on the level, slope and curvature factors. For the 3-month LIBOR rate, the slope factor is the dominant factor. It explains $59.34 \%$ of the variance. The level factor also explains $31.78 \%$. Therefore, the LIBOR rate is driven by the slope and level factors. For the 2-year swap rate, the level explains $94.11 \%$ and the curvature explains $4.29 \%$. For the 10 -year swap rate, the level explains $94.81 \%$ and the curvature explains $2.57 \%$. So the swap rates are mainly driven by the level factor, with other factors having little explanatory power.

\section{Empirical Results}

\section{C.1 One-Factor CIR Model}

The one-factor CIR model is estimated first. Only one observed LIBOR or swap rate is needed to recover the unobservable state variable. The 3-month LIBOR rate and 2and 10-year swap rates were tested, and the 2-year swap rate gave the smallest fitting errors for all other LIBOR and swap rates. Table 1 reports the estimated parameter values.

For the one factor model, the state variable is the instantaneous default-adjusted rate, or the short rate itself. The long-run mean, $y_{0}$, of the short rate is estimated at $6.747 \%$. The speed of adjustment $k$ is estimated at 0.05532 . The conditional mean and variance of the short rate for the one-factor model are given by:

$$
E\left(R_{\tau} \mid R_{t}\right)=\theta+\left(R_{t}-\theta\right) e^{-k(\tau-t)}
$$




$$
\operatorname{var}\left(R_{\tau} \mid R_{t}\right)=\frac{\sigma^{2}}{2 k}\left[\theta+2\left(R_{t}-\theta\right) e^{-k(\tau-t)}-\left(2 R_{t}-\theta\right) e^{-2 k(\tau-t)}\right]
$$

The marginal density of process is

$$
\pi(x)=\frac{1}{b^{a} \Gamma(a)} x^{a-1} e^{-x / b}, \quad a=\frac{v}{2}, b=\frac{2 \theta}{v},
$$

where $\mathrm{v}$ is defined in (2.29). This is a gamma distribution $\Gamma(x ; a, b)$. The steady state has a mean and standard deviation of $\theta$ and $\sigma \sqrt{\frac{\theta}{2 k}}$ respectively, which are the limits of (3.12) and (3.13) as $\tau$ goes to infinity.

The "half-life" of the process (the time when the short rate is expected to reach a value halfway between the current level and the long-run mean), is $\ln 2 / k$, or roughly 12.5 years. This implies weak mean reversion.

For the estimated parameter values the implied long-term yield, as defined in (2.16), is $8.929 \%$ (see Table 1, Panel B). The absolute value of the pricing (fitting) errors (Table 2, Panel A) for the 3-month LIBOR and the 10-year swap rates have means of 33.853 and 18.610 basis points respectively. Those for other swap rates have smaller means but still large standard errors. With typical bid-ask spreads in the swap market during this period of about four basis points, this pricing error is very large. We also report the mean and standard deviation of the weekly changes in LIBOR and swap rates. In Table 2, Panel B, we find that the one-factor CIR model is unable to match the volatility of the changes in LIBOR and long-term swap rates. The sizable pricing errors can be taken as evidence against the one factor CIR model.

To test whether the recovered values of the state variable have the conditional and marginal densities implied by the estimated parameters, we calculate test statistics for the conditional moments. If a $n$-dimensional vector $g$ has an asymptotic normal distribution, $N(0, \Omega)$, then the test statistic is given by:

$$
g^{\prime} \Omega^{-1} g \rightarrow \chi^{2}(n) .
$$

To construct this test for the conditional distribution of the CIR state variable, we use the following three moment conditions as the $g$ function

$$
\begin{aligned}
& E\left[R_{t+1}-\mu_{1 t}\right]=0, \\
& E\left[\left(R_{t+1}-\mu_{1 t}\right) R_{t}\right]=0, \\
& E\left[\left(R_{t+1}-\mu_{1 t}\right)^{2}-\mu_{2 t}\right]=0, E\left[\left(\left(R_{t+1}-\mu_{1 t}\right)^{2}-\mu_{2 t}\right) R_{t}\right]=0,
\end{aligned}
$$

where $\mu_{1 t}$ and $\mu_{2 t}$ are the first and second conditional moments defined by (3.12) and (3.13) for $\tau=t+1$. The asymptotic covariance matrix $\Omega$ is estimated using the NeweyWest procedure. We use the square root of the 233 observations, or 15, as the window width in Newey-West procedure. The test statistic is 8.9117 (Table 1, panel A, Test 1 column) for the one factor model. Since the 5\% critical value for chi-square distribution with four degrees of freedom is 9.49 , we cannot reject the hypothesis at the conventional level that the sample conditional first and second moments are indeed the ones implied by the estimated parameter values. 
Table 4, Panel $\mathrm{C}$ reports the R-square values from the regression of the previously defined three main factors on changes in the recovered state variable. The value 0.9402 shows that the state variable captures the level factor.

\section{C.2 Two-Factor Model}

We now continue with the estimation of the two-factor CIR model. Two rates need to be matched to recover the state variables. Table 1 reports the results when 2- and 10-year swap rates are used to recover the state variables.

The risk premia for both state variables are negative. The estimated parameters imply a long rate of $5.330 \%$. The two-factor model generates a long run mean of the short rate of $3.546 \%$.

From Table 2 we can see that the pricing errors of the two-factor model are much smaller than that for the one-factor model. The mean absolute pricing errors for the 3- and 5 -year swap rates are both less than the bid-ask spread (about four basis points), while the mean absolute pricing error for the fitted LIBOR rate is not. This is encouraging since it seems that the swap market can be priced by a two-factor equilibrium model. The LIBOR rate is still not well fitted. This suggests that the short-term rate has distinctive features that the dynamics of the intermediate and long-term rates do not capture (see Figure 1), the 3-month LIBOR behaves considerably different from the swap rates. Figure 2 illustrates differences in behavior between observed and fitted (using 2-factor specification) 3-month LIBOR rates. When comparing Figures 1 and 2 we can see that the largest discrepancies occur when the yield curve has negative slope (for example October, 1995 - March, 1996 and September, 1998 - December, 1998). One possible explanation could be that even a 2-factor model does not correctly capture the slope component.

The correlation of the changes of the two state variables is, 0.0013 (see Table 1, Panel B). Remember that in the model we assume the two factors were independent. Therefore, this evidence does not contradict the model specifications.

The test statistic $^{3}$ for the null hypothesis that the sample conditional first and second moments are consistent with those implied by the estimated parameter values is 4.6567 for the first variable and 6.4909 for the second variable. So again we cannot reject the hypothesis that the sample conditional first and second moments are indeed the ones implied by the estimated parameter values.

Table 4, Panel $\mathrm{C}$ reports $\mathrm{R}$-square values from regressing the level, slope and curvature factors on the changes in the two recovered state variables. The level factor is mainly explained by the second state variable and the curvature by the first. The first factor also explains a significant portion of the slope factor. If we include both state variables, the level factor is almost entirely explained as well as most of the curvature factor. The slope factor, however, is not captured by the two state variables. Furthermore,

\footnotetext{
${ }^{3}$ We can extend one-factor specification test to multifactor models because we assume that factors are not correlated. For multifactor models we do the test separately for each factor and $R_{t}$ refers to the respective state variable.
} 
the R-square values are in line with the independency result: the first factor explains changes of slope and curvature factors but not the level factor.

Note that we would expect either a positive or zero constant as the lower bound for the nominal rate. The estimated value of the constant is negative and statistically significantly different from zero, $-0.25495(0.00003)$. This suggests that the short rate is too volatile even at low interest rate levels to be consistent with the standard CIR specification where the constant is equal to zero.

\section{C.3 Three-Factor Model}

We now continue to observe if adding another factor into the CIR framework significantly improves the performance. In Figure 3, with the 3-factor specification, we can closely fit the volatility curve. Table 1 gives the estimation results when the 3 -month LIBOR, and 2- and 10-year swap rates are matched to recover three state variables. The long-run mean of the short rate is estimated at $6.244 \%$ and the long-term yield is $6.257 \%$. The risk premia are all negative, but not estimated with sufficient precision. Correlations among the three state variables are $-0.35,-0.50$, and -0.58 respectively. Thus the independence assumption is violated as we increase the number of variables. Table 2 , Panel $\mathrm{C}$ reports additional inconsistencies between theoretical models and estimation results. We assume that the autocorrelations of rates' pricing errors to be zeros but as one can see from the table they are significantly positive. We have tried to estimate a model with autocorrelated pricing errors, but it did not converge.

The tests cannot reject the hypothesis that the conditional means and variances of the factors are as given by their assumed theoretical distribution.

As can be seen from Table 4, by increasing the number of factors to three, we capture all three factors (level, slope and curvature) estimated by the principal component analysis. While the mean absolute pricing errors are all either smaller than the bid-ask spread or pretty close to it, we are unable to justify our assumption that the factors are independent. The negative value for the estimated constant term suggests that the square root process is unable to provide a good description of the volatility: the volatility is rather large even when the rate is close to zero. Hence the dependence of volatility on the level of the state variables could also be higher than that suggested by a square root process.

\section{Out of Sample Performance}

To test these specifications we apply estimated models to another data set containing 3-month LIBOR and 2-, 3-, 5-, 7- and 10-year swap rates. This data set covers the period from April 7, 1989 till September 12, 1997. We obtained the LIBOR and swap rates from Bloomberg. 
As in the earlier sections, we assumed no pricing errors for some of the swap rates and inverted the pricing functions to obtain the state variables for each point in time. For example, for a 3-factor specification, 3-month LIBOR, and 2- and 10-year swap rates were used. As we can see from Table 3, the results, in particular for a 3-factor model, are surprisingly good. The mean absolute pricing errors are comparable with the ones for the original data set. For a 3-factor model two out of three figures (3-and 7-year swap rates) are less than bid-ask spread of about four basis points and the remaining one is 4.629 basis points. These pricing errors are comparable to those reported by Dai and Singleton (1999) for models that belong to the more general affine term-structure class that nests the CIR specification. Their data set contains 6-month LIBOR and 2-, 3-, 5-, 7-, and 10year swap rates and covers the period from April 3, 1987 till August 23, 1996. The lowest means of pricing errors they report for 3-, 5-, and 7-year swaps are -11.3, 16.9, and -12.7 basis points, respectively.

\section{E. Prediction of Future Spot Rates}

We use equation (3.13) to find the expected value of the state variable to evaluate the predictive power, regress the actual monthly changes in rates on a constant and the predicted 3-month change in rates. We use the change in rates instead of the level of rates because the LIBOR and swap rates are persistent. A good model would have an intercept $a$ close to zero and a regression coefficient $b$ close to one. Table 5 reports the results.

For the prediction of the 3-month LIBOR, all three models generate an intercept insignificantly different from zero and a coefficient $\mathrm{b}$ insignificantly different from one. However, for all specifications R-square is small, the one-factor model has the largest Rsquare of $13.30 \%$.

For the 2-year swap rate, only one of the intercepts (the two-factor model) is insignificantly different from zero but the corresponding slope coefficient is significantly different from one. For other models both estimated parameters are off.

For the $10 \mathrm{Y}$ swap rate, the intercept is insignificantly different from zero for the one-factor model, but the slope coefficients for all three models are significantly different from one. To summarize the preceding discussion, we can say that to go to three factors does not appear to improve the performance when it comes to forecasting future swap rates.

Notice that the one-factor model performs best in forecasting 3-month changes for the 3-month LIBOR, this happens though the three-factor model was forced to match the 3-month LIBOR rate. The three-factor model does worst, again showing that something is missing in the model specifications. The pattern continues forecasting three-month changes in 2- and 10-year swap rates. 


\section{Valuation of Caps and Swaptions}

So far we have been focusing on the LIBOR and swap rates. We have used correlation, conditional distributions, and predictive power as evidence against the multifactor CIR models. To evaluate the economic importance of the statistical evidence against the models reported in the earlier sections, we examine the models' pricing errors for caps and swaptions.

\section{A. Pricing Errors of Caps Using CIR Models}

The weekly cap data, obtained from Fannie Mae, consists of bid prices from February 17, 1995 to July 16, 1999. Cap maturities are 1-, 2-, 5-, and 10-years. All contracts are at the money -, i.e., the strike rate is the spot rate for the corresponding maturity. The original data is quoted as the Black's volatility, we transform it into price data using Black's formula. For this purpose, we obtain the data for LIBOR zero coupon bonds from University Capital Strategies Group, Minneapolis, Minnesota. The forward rate is computed from these LIBOR zeros. We compute the strike from the forward rates. The derived price is in basis points, or cents per $\$ 100$ face value of the cap contract. The typical bid-ask spread is one to two percent in Black's volatility. We also transform this bid-ask spread in volatility into that in basis points using Black's formula.

Table 6, Panel A reports the means and standard deviations of the cap prices during this period, along with the average bid-ask spreads. The average price is only 19.60 basis points for the one-year contract, but 638.20 basis points for the ten-year contract. Although the 10-year cap has only ten times the individual caplets that the 1year cap has. The longer maturity caplets are more valuable, so that the average price of the 10-year cap is about 30 times that of the 1-year contract. If you compare the price of a 5-year and 10-year cap, you will find that the relative price difference is close to the difference in the number of caplets in each contract. This is because the 5-year cap also has many long-maturity caplets. Beyond five years, although the longer maturity caplet is still more valuable, the difference is small. An average bid-ask spread in the cap market is $8 \%$ to $10 \%$ of the price, which implies a very illiquid market. The shorter maturity price is more volatile than the longer maturity price. For 5- and 10-year contracts, the volatility is just about $50 \%$ larger than the bid-ask spread, but for the 1-year contract, the volatility is more than three times the bid-ask spread.

Table 6, Panel A also reports the mean absolute pricing errors from using the estimated CIR models in the previous section. The 1-year cap computed using two-factor model has pricing error larger than those of one-factor. This is surprising, given that the two-factor model fit the LIBOR and swap rates more precisely than the one-factor model. However, the negative value for the constant term suggests that the two-factor model is misspecified. The pricing errors for longer maturities are better with two-factor model, for 2-, 5-, and 10-year caps they are about twice as low as the ones for one-factor model. So the one-factor model outperforms the two-factor model on the short end but loses a lot for all other maturities. 
The three-factor model, in Table 6, does not do as well as the two-factor model for 1- and 2-year caps. However, pricing errors for 5- and 10-year caps are 30-35\% lower than those for the two-factor model.

Overall, no CIR model can price the cap consistently into the bid-ask spread, and all CIR models are misspecified. Thus, it also could be viewed that by increasing the number of factors we lose the descriptive power on the short end and gain with longer maturity caps. Comparing Figures 1 and 4, we can see that estimated caps prices behave very differently for both 1 - and 3-factor models when the yield curve has negative slope. This observation suggests, the CIR specification does not capture the interaction between the intertemporal dynamics of level and slope.

\section{B. Joint Estimation}

In order to test how information contained in caps prices data relates to the term structure we also did joint estimation. Sum of caps' absolute pricing errors was added to the likelihood function. The results of these computations for two- and three-factor models are reported in the Table 1'. As we can see from Table 1 and Table 1' comparison the coefficients for state variables processes are basically the same. Assigning larger weights to the sum of caps' absolute pricing errors did not result in any significant change. One possible reason for this outcome could be the LIBOR and swap rates alone do not span the fixed income related instruments, as it was mentioned before in the literature, see for example Collin-Dufresne and Goldstein (2001). Another possible reason could be the shortcomings of CIR models. Although the models we use are multifactor ones the structure imposed by CIR specification is quite nonflexible. We will illustrate this point using Dai and Singleton (1999) framework a bit later when we will talk about stochastic volatility in CIR models.

\section{Pricing Errors of Swaptions Using CIR Models}

The weekly swaption data, obtained from Fannie Mae, consists of bid prices from February 17, 1995 to July 16, 1999. The swaption maturities are 3-months and 2-years and the underlying swap lengths are 2-, 5- and 10-years. All contracts are at the money and of receiver type. The original data is quoted as the Black's volatility. We transform it into price using Black's formula. Prices of LIBOR zero coupon bonds are used to compute the forward swap rate. We compute the forward swap rate such that the forward swap contract has a value of zero at the future entering date, by assuming the forward LIBOR is realized. The transferred price is in basis points, or cents per $\$ 100$ face value of the swaption contract. The typical bid-ask spread is one to two percent in Black's volatility. We also transform this bid-ask spread in volatility to one in price.

Table 6, Panel B reports the means and standard deviations of swaption prices during this period, along with the average bid-ask spread. The average price of a 2-year contract is about 2.5 times the price of a 3-month contract with the same underlying swap length. The average bid-ask spread in the swaption market is approximately $8 \%$ to $10 \%$ of 
the price, similar to those in the cap market. Three-month contracts are more volatile than the 2-year contracts. For those contracts that have the same maturity but different underlying swap lengths, the ones that have shorter underlying swap lengths are more volatile. For all the contracts, the volatility and bid-ask spread are of the same order. We can say that the swaption price is relatively stable over time.

Table 6, Panel B also reports pricing errors using the estimated CIR models. The one-factor model did reasonably well, pricing 3-month swaptions with an underlying swap length of two years, specifically contract 3M2Y. Nevertheless it produces large pricing errors for all other contracts and every time the one-factor model gives us more volatile swaption prices. As in the cap market, the one-factor model can be used to price short-term swaptions, both as to swaption maturity and underlying swap length. The twofactor model considerably improves the pricing errors for long-term swaptions. The pricing errors are still large when compared with the typical bid-ask spread in this market. Standard deviations of fitted prices produced by the three-factor model are too low compared to the observed swaption prices standard deviations. The conclusion is that none of the models capture the processes driving the pricing of swaptions well enough. Although the one-factor model cannot capture the long rate well, it can be used to price the shorter maturity swaptions. The two-factor model prices the longer maturity swaptions better, but still the pricing errors are too large. Similar to the caps, comparing Figures 1 and 5, we can see that the biggest differences in behavior are during the negative sloped yield curve.

\section{Slope of Term Structure and Models' Specification}

As we already mentioned in subsection 4.A estimated caps prices seem to be behave very different from market prices. To test that observation we run regressions of the following form

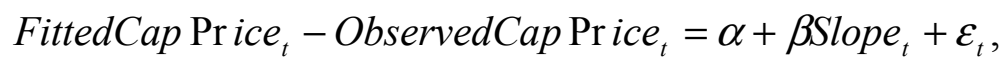

where for Slope $e_{t}$ we have two options: the short end slope, the difference between 2-year swap and 3-month LIBOR rates, and the yield curve slope, the difference between 10-year swap and 3-month LIBOR rates. The results for these regressions are reported in the Table 7. As we can see there is certain dependence between pricing errors and slope of the term structure. It is especially evident for the latter choice of slope variable, in this case all p-values are very close to zero. With the three factor CIR model we force fit 3month LIBOR, 2-year swap, and 10-year swap rates so this particular model produces exactly the same slopes as we observe in data but even model demonstrates strong dependence of pricing errors on slope. Again it suggests that CIR models fail in capturing intertemporal dynamics of slope. Regression coefficients for 1-year cap are positive. Also on average this cap is overpriced by all three models. Therefore as term structure slope starts decreasing the pricing error starts shrinking and if term structure becomes more negatively sloped the 1-year cap may become underpriced. On the other hand 10-year cap 
is underpriced by all models and all regression coefficients are positive. Hence the pricing error for 10-year cap also starts decreasing in absolute value as slope becomes smaller and at some point this cap may become overpriced. So although the coefficients differ in sign the cap prices behave the same way as the structure flattens the caps become more precisely priced.

We also extend our chi-square test of subsection 3.C.1 and add one moment condition that includes slope

$$
E\left[\left(\left(R_{t+1}-\mu_{1 t}\right)^{2}-\mu_{2 t}\right) \text { Slope }_{t}\right]=0 .
$$

These new test statistics are reported in the Table 1 in the Test 2 column. As we can see now all three specifications (one-, two-, and three-factor CIR models) are rejected at .5\% significance level.

\section{E. Stochastic volatility in CIR models}

With the three-factor CIR model we can force-fit term structure of interest rates with good precision but as we already pointed out the model has difficulty replicating standard deviations of caps and swaptions prices. Caps and swaptions are volatility instruments and they are even quoted in terms of Black volatility. So problem with correct pricing could be inability of CIR specifications to deal with stochastic volatility.

To demonstrate CIR models flaws let us apply Dai and Singleton (1999) framework. The general identified AY $(3,3)$ model is

$$
d Y(t)=\left(\begin{array}{c}
k_{1}\left(\theta_{1}-Y_{1}\right) \\
k_{2}\left(\theta_{2}-Y_{2}\right) \\
k_{3}\left(\theta_{3}-Y_{3}\right)
\end{array}\right) d t+\Sigma_{3 \times 3}\left(\begin{array}{l}
\sqrt{\alpha_{1}+\beta_{1}^{\prime} \cdot Y(t)} d W_{1} \\
\sqrt{\alpha_{2}+\beta_{2}^{\prime} \cdot Y(t)} d W_{2} \\
\sqrt{\alpha_{3}+\beta_{3}^{\prime} \cdot Y(t)} d W_{3}
\end{array}\right) .
$$

For multifactor CIR model $\left(\beta_{1}, \beta_{2}, \beta_{3}\right)$ is diagonal. We assume that the factors are not correlated so $\Sigma_{3 \times 3}$ is diagonal as well. Therefore the model we study is

$$
d Y(t)=\left(\begin{array}{c}
k_{1}\left(\theta_{1}-Y_{1}\right) \\
k_{2}\left(\theta_{2}-Y_{2}\right) \\
k_{3}\left(\theta_{3}-Y_{3}\right)
\end{array}\right) d t+\left(\begin{array}{c}
\sigma_{1} \sqrt{Y_{1}} d W_{1} \\
\sigma_{2} \sqrt{Y_{2}} d W_{2} \\
\sigma_{3} \sqrt{Y_{3}} d W_{3}
\end{array}\right) .
$$

$\operatorname{The} \operatorname{Ar}(3,3)$ equivalent of the model above is

$$
\left(\begin{array}{c}
d r_{t} \\
d \theta_{t} \\
d v_{t}
\end{array}\right)=\left(\begin{array}{c}
k_{1}\left(\theta_{t}-r_{t}\right) \\
k_{2}\left(\bar{\theta}+v_{t}-\theta_{t}\right) \\
k_{3}\left(\bar{v}-v_{t}\right)
\end{array}\right) d t+\left(\begin{array}{ccc}
1 & 1 & 1 \\
& 1-k_{2} / k_{1} & 1-k_{3} / k_{1} \\
& & \left(1-\frac{k_{3}}{k_{1}}\right)\left(1-\frac{k_{3}}{k_{2}}\right)
\end{array}\right)\left(\begin{array}{c}
\sigma_{1} \sqrt{r_{t}+a_{1} \theta_{t}+b_{1} v_{t}+c_{1}} d W_{1}(t) \\
\sigma_{2} \sqrt{a_{2} \theta_{t}+b_{2} v_{t}+c_{2}} d W_{2}(t) \\
\sigma_{3} \sqrt{b_{3} v_{t}} d W_{3}(t)
\end{array}\right),
$$

where

$$
r_{t}=Y_{1}(t)+Y_{2}(t)+Y_{3}(t)+\bar{y},
$$




$$
\begin{aligned}
& \theta_{t}=\left(1-k_{2} / k_{1}\right) Y_{2}(t)+\left(1-k_{3} / k_{1}\right) Y_{3}(t)+\theta_{1}+\left(k_{2} \theta_{2}+k_{3} \theta_{3}\right) / k_{1}+\bar{y}, \\
& v_{t}=\left(1-k_{3} / k_{1}\right)\left(1-k_{3} / k_{2}\right) Y_{3}(t), \\
& \bar{\theta}=\theta_{1}+\theta_{2}+k_{3} \theta_{3} / k_{1}+\bar{y}, \\
& \bar{v}=\left(1-k_{3} / k_{1}\right)\left(1-k_{3} / k_{2}\right) \theta_{3} .
\end{aligned}
$$

The variables $r_{t}, \theta_{t}$, and $v_{t}$ are traditionally called short rate, stochastic central tendency, and stochastic volatility, respectively. This transformation allows us to see why we may have problems with modeling: the stochastic volatility $v_{t}$ appears in the drift of $\theta_{t}$.

In contrast the following $\mathrm{AY}(3,2)$ model has nice interpretation of level, stochastic central tendency and stochastic volatility

$$
d Y(t)=\left(\begin{array}{c}
k_{1}\left(0-Y_{1}\right) \\
k_{2}\left(\theta_{2}-Y_{2}\right) \\
k_{3}\left(\theta_{3}-Y_{3}\right)
\end{array}\right) d t+\left(\begin{array}{ccc}
1 & \sigma_{12} & \sigma_{13} \\
& 1 & \\
& & 1
\end{array}\right)\left(\begin{array}{c}
\sqrt{Y_{3}} d W_{1} \\
\sqrt{\alpha_{2}+\beta_{22} Y_{2}} d W_{2} \\
\sqrt{\beta_{33} Y_{3}} d W_{3}
\end{array}\right),
$$

which becomes more evident from its Ar form

$$
\left(\begin{array}{c}
d r_{t} \\
d \theta_{t} \\
d v_{t}
\end{array}\right)=\left(\begin{array}{l}
k_{1}\left(\theta_{t}-r_{t}\right) \\
k_{2}\left(\bar{\theta}-\theta_{t}\right) \\
k_{3}\left(\bar{v}-v_{t}\right)
\end{array}\right) d t+\left(\begin{array}{ccc}
1 & \sigma_{r \theta} & \sigma_{r v} \\
& 1 & \\
& & 1
\end{array}\right)\left(\begin{array}{c}
\sqrt{v_{t}} d W_{1}(t) \\
\sqrt{a+\varsigma^{2} \theta_{t}} d W_{2}(t) \\
\xi \sqrt{v_{t}} d W_{3}(t)
\end{array}\right),
$$

where

$$
\begin{aligned}
& r_{t}=Y_{1}(t)+Y_{2}(t), \\
& \theta_{t}=\left(1-k_{2} / k_{1}\right) Y_{2}(t)+k_{2} \theta_{2} / k_{1}, \\
& v_{t}=Y_{3}(t), \\
& \bar{\theta}=\theta_{2}, \quad \bar{v}=\theta_{3} .
\end{aligned}
$$

The models of this type could a way to pursue, though there may be other roadblocks, for example Chen (1996) model is from that class $\left(a=0, \quad \sigma_{r \theta}=\sigma_{r v}=0\right)$ but it was rejected by Dai and Singleton (1999) based solely on interest rates data. 


\section{Conclusion}

In this paper we investigate the ability of one-, two- and three-factor CIR models to describe the dynamics of the LIBOR and swap markets. We estimate the model parameters using the maximum likelihood method and time series data on LIBOR and swap rates. Using the estimated model parameters, we predict the future LIBOR and swap rates and compare them with realized rates. We then use the estimated model to price interest rate derivatives, specifically caps and swaptions, and to compute the resulting pricing error.

Although the use of more factors fits the LIBOR and swap rates more precisely, the statistical properties of the estimated factors are not consistent with the properties implied by the model. In particular, we found that in the three-factor model the factors are correlated, contradicting the assumption that they are independent. The constant term in all three models (a short rate is the sum of the factor(s) plus a constant) is estimated to be negative. We added a constant term so that nominal interest rates would be bounded away from zero. Why is the constant negative? The short interest rate volatility falls to zero at very low levels in the CIR specification without a constant. However, in the data (see, for example, Figure 1) the short (3-month LIBOR) rate volatility is still high at the lowest levels suggesting that the volatility fall with level may be too high in the CIR model without a constant. By adding a negative constant the volatility of the short rate at low levels can still be kept sufficiently high to match what we observe in the data. This clearly suggests that the CIR specification may have to be modified. Also notice that the constant becomes more negative with a number of factors. This fact provides an additional indicator that just increasing the number of factors in the CIR model is not going to help.

When used to predict future LIBOR and swap rates, we found there are more indications of model misspecification. When used to value interest rate derivatives, specifically caps and swaptions, no CIR model can correctly price all contracts simultaneously. Although the one factor model is clearly deficient, it is the best among all the CIR models considered for the pricing of short maturity caps and swaptions. However, the pricing error is still too large relative to the typical bid-ask spread. More factors may help improve the pricing of longer term caps and swaptions, although again the pricing error is large compared with the bid-ask spread. Adding these factors makes the pricing of short-term contracts worse. In other words, the stochastic process for the factors may be misspecified. While it is possible to satisfactorily fit the term structure of swap rates by increasing the number of factors to three, the fitting errors for short maturity caps and swaptions in fact become larger with more factors.

Clearly the models cannot capture the cap and swaption prices around the LTCM failure date (see Figures 4 and 5). During the periods when the short rate was relatively stable the models' movements in the cap and swaption prices closely resemble the movements in the market prices of caps and swaptions. The largest differences in behavior between actual and modeled prices are where the yield curve has a negative slope. These observations suggest that the models have a problem with simultaneously matching the dynamics of the level of the short rate and the slope of the yield curve as pointed out by Duffee (2000). In order to satisfactorily value derivative claims, we need 
richer term structure models that satisfactorily capture the time series properties of the spot rates and risk premia. Several alternatives to the CIR specification have been proposed in the literature, for example, Anderson and Lund (1997), Dai and Singleton (1999), Duarte (2000), and Duffee (2000). Attari (1999) suggests a three factor -- four state variable model, where the short rate is assumed to be a sum of two instantaneously perfectly negatively correlated state variables. Using these models for valuing derivative claims involve complex and time consuming computational methods. Therefore an examination of the extent to which these models are suitable for valuing derivative claims is left for future research. 


\section{Table 1. Estimates of Multi-Factor CIR Model Using LIBOR and Swap Rates}

These tables show the estimated parameters and implied rates for one-, two-, and three-factor CIR models. All models are estimated using 3-month LIBOR and 2-, 3-, 5-, 7-, and 10-year swap rates over the period from $2 / 3 / 1995$ to $7 / 16 / 1999$. The quasi-maximum log-likelihood method was used for estimation. The results are presented in the following form: estimated parameter (standard error).

\section{A. Factor Parameters}

The percentiles for chi-square distribution with 4 degrees of freedom (test 1$)$ are 7.78 (10\% confidence interval) and 9.49 (5\% confidence interval) and the percentiles for chi-square distribution with 5 degrees of freedom (test 2) are 9.24 (10\% confidence interval), 11.07 (5\% confidence interval) and $16.75(.5 \%$ confidence interval). Test 1 includes four moment conditions as described on page 14 and Test 2 includes five moment conditions as described on page 20 .

\begin{tabular}{ccccccc}
\hline & $\boldsymbol{\kappa}$ & $\boldsymbol{\theta}$ & $\boldsymbol{\sigma}$ & $\boldsymbol{\lambda}$ & Test 1 & Test 2 \\
\hline One-Factor & & & & & & \\
$Y$ & 0.05532 & 0.09615 & 0.02702 & -0.01854 & 8.9117 & 20.8347 \\
& $(0.04522)$ & $(0.11615)$ & $(0.01806)$ & $(0.04068)$ & & \\
\hline Two-Factor & & & & & & \\
$Y_{I}$ & 0.39269 & 0.27315 & 0.01553 & -0.00038 & 4.6567 & 5.8826 \\
& $(0.03172)$ & $(0.00003)$ & $(0.00091)$ & $(0.01765)$ & & \\
$Y_{2}$ & 0.05205 & 0.01626 & 0.03906 & -0.05789 & 6.4909 & 79.4120 \\
& $(0.03486)$ & $(0.01059)$ & $(0.00633)$ & $(0.03492)$ & & \\
\hline Three-Factor & & & & & & \\
$Y_{I}$ & 3.96377 & 0.52095 & 0.01930 & -0.00767 & 4.2478 & 8.6076 \\
& $(0.38200)$ & $(0.23463)$ & $(0.00435)$ & $(0.03411)$ & & \\
$Y_{2}$ & 0.03424 & 0.15236 & 0.02607 & -0.00301 & 5.5523 & 133.4975 \\
$Y_{3}$ & $(0.09165)$ & $(0.46651)$ & $(0.02523)$ & $(0.09002)$ & & \\
& 0.37520 & 0.37601 & 0.01826 & -0.01972 & 4.6755 & 8.9600 \\
& $(0.04571)$ & $(0.10268)$ & $(0.00294)$ & $(0.04287)$ & & \\
\hline
\end{tabular}

\section{B. Derived Model Parameters}

The table reports estimates of constant, $\bar{y}$, values of log-likelihood function, factors correlations, and implied short and long rates.

\begin{tabular}{cccccccc}
\hline & $\bar{y}$ & $\mathbf{y}_{\mathbf{0}}$ & $\mathbf{y}_{\infty}$ & $\mathbf{L o g L}$ & Corr $_{12}$ & Corr $_{23}$ & Corr $_{13}$ \\
\hline One-Factor & -0.02868 & 0.06747 & 0.08977 & 7280.70 & & & \\
& $(0.01892)$ & & & & & & \\
\hline Two-Factor & -0.25395 & 0.03546 & 0.05330 & 8314.27 & 0.0013 & & \\
& $(0.00003)$ & & & & & & \\
\hline Three-Factor & -0.98689 & 0.06244 & 0.06257 & 8513.61 & -0.35 & -0.50 & -0.58 \\
& $(0.00005)$ & & & & & & \\
\hline
\end{tabular}


Table 1'. Estimates of Multi-Factor CIR Model Using LIBOR and Swap Rates, and Cap Prices

These tables show the estimated parameters and implied rates for two- and three-factor CIR models. All models are estimated using 3-month LIBOR and 2-, 3-, 5-, 7-, and 10-year swap rates over the period from 2/3/1995 to 7/16/1999, and 1-, 2-, 5-, and 10-year cap prices. The quasi-maximum log-likelihood method was used for estimation. The results are presented in the following form: estimated parameter (standard error).

\section{A. Factor Parameter}

\begin{tabular}{ccccc}
\hline & $\boldsymbol{\kappa}$ & $\boldsymbol{\theta}$ & $\boldsymbol{\sigma}$ & $\boldsymbol{\lambda}$ \\
\hline Two-Factor & & & & \\
$Y_{1}$ & 0.39220 & 0.27274 & 0.01534 & -0.00038 \\
& $(0.01724)$ & $(0.15365)$ & $(0.00247)$ & $(0.00435)$ \\
$Y_{2}$ & 0.05319 & 0.01619 & 0.04302 & -0.05917 \\
& $(0.02015)$ & $(0.00140)$ & $(0.00369)$ & $(0.01814)$ \\
\hline Three-Factor & & & & \\
$Y_{1}$ & 3.97490 & 0.52205 & 0.04140 & -0.02990 \\
$Y_{2}$ & $(1.04442)$ & $(0.28391)$ & $(0.01492)$ & $(0.15550)$ \\
& 0.03439 & 0.15567 & 0.02470 & -0.00304 \\
$Y_{3}$ & $(0.07936)$ & $(0.44937)$ & $(0.02403)$ & $(0.07840)$ \\
& 0.37531 & 0.37307 & 0.03320 & -0.01657 \\
& $(0.15012)$ & $(0.16397)$ & $(0.01108)$ & $(0.14512)$ \\
\hline
\end{tabular}

\section{B. Derived Model Parameters}

The table reports estimates of constant, $\bar{y}$, values of log-likelihood function, factors correlations, and implied short and long rates.

\begin{tabular}{cccccccc}
\hline & $\bar{y}$ & $\mathbf{y}_{\mathbf{0}}$ & $\mathbf{y}_{\infty}$ & $\mathbf{L o g L}$ & Corr $_{12}$ & Corr $_{23}$ & Corr $_{13}$ \\
\hline Two-Factor & -0.22893 & 0.06000 & 0.07510 & 7566.63 & -0.67 & & \\
& $(0.11022)$ & & & & & & \\
\hline Three-Factor & -0.98960 & 0.06118 & 0.06178 & 7481.69 & -0.09 & -0.89 & -0.29 \\
& $(0.00015)$ & & & & & & \\
\hline
\end{tabular}


Table 2. Observed and Fitted LIBOR and Swap Rates

The tables present the actual and implied LIBOR and swap rates. The estimated parameters used for computations are shown in Table 1. The numbers in bold represent the results for exactly fitted rates, so they should be exactly the same as the corresponding market figures. We also report implied autocorrelation in the LIBOR and swap rates' pricing errors.

\section{A. Level of LIBOR and Swap Rates}

\begin{tabular}{ccccccc}
\hline & $\mathbf{3 M}$ & $\mathbf{2 Y}$ & $\mathbf{3 Y}$ & $\mathbf{5 Y}$ & $\mathbf{7 Y}$ & $\mathbf{1 0 Y}$ \\
\hline MEAN (\%) & & & & & & \\
Market & 5.627 & 5.966 & 6.093 & 6.254 & 6.444 & 6.513 \\
One-Factor & 5.742 & $\mathbf{5 . 9 6 6}$ & 6.062 & 6.235 & 6.387 & 6.578 \\
Two-Factor & 5.677 & $\mathbf{5 . 9 6 6}$ & 6.075 & 6.246 & 6.372 & $\mathbf{6 . 5 1 3}$ \\
Three-Factor & $\mathbf{5 . 6 2 7}$ & $\mathbf{5 . 9 6 6}$ & 6.083 & 6.259 & 6.384 & $\mathbf{6 . 5 1 3}$ \\
\hline STD (\%) & & & & & & \\
Market & 0.322 & 0.514 & 0.534 & 0.551 & 0.538 & 0.565 \\
One-Factor & 0.524 & $\mathbf{0 . 5 1 4}$ & 0.506 & 0.488 & 0.471 & 0.448 \\
Two-Factor & 0.512 & $\mathbf{0 . 5 1 4}$ & 0.522 & 0.540 & 0.554 & $\mathbf{0 . 5 6 5}$ \\
Three-Factor & $\mathbf{0 . 3 2 2}$ & $\mathbf{0 . 5 1 4}$ & 0.538 & 0.559 & 0.567 & $\mathbf{0 . 5 6 5}$ \\
\hline M.A.E (bps) & & & & & & \\
One-Factor & 33.853 & $\mathbf{0 . 0 0 0}$ & 6.058 & 11.518 & 15.327 & 18.610 \\
Two-Factor & 31.179 & $\mathbf{0 . 0 0 0}$ & 2.651 & 2.280 & 7.248 & $\mathbf{0 . 0 0 0}$ \\
Three-Factor & $\mathbf{0 . 0 0 0}$ & $\mathbf{0 . 0 0 0}$ & 1.692 & 1.608 & 6.403 & $\mathbf{0 . 0 0 0}$ \\
\hline
\end{tabular}

*M.A.E: mean absolute pricing error.

\section{B. Weekly Changes of LIBOR and Swap Rates}

\begin{tabular}{ccccccc}
\hline & $\mathbf{3 M}$ & $\mathbf{2 Y}$ & $\mathbf{3 Y}$ & $\mathbf{5 Y}$ & $\mathbf{7 Y}$ & $\mathbf{1 0 Y}$ \\
\hline MEAN (bps) & & & & & & \\
Market & -0.437 & -0.676 & -0.673 & -0.651 & -0.545 & -0.603 \\
One-Factor & -0.686 & $\mathbf{- 0 . 6 7 6}$ & -0.664 & -0.641 & -0.619 & -0.590 \\
Two-Factor & -0.706 & $\mathbf{- 0 . 6 7 6}$ & -0.659 & -0.635 & -0.619 & $\mathbf{- 0 . 6 0 3}$ \\
Three-Factor & $\mathbf{- 0 . 4 3 7}$ & $\mathbf{- 0 . 6 7 6}$ & -0.675 & -0.655 & -0.632 & $\mathbf{- 0 . 6 0 3}$ \\
\hline STD (bps) & & & & & & \\
Market & 5.036 & 10.145 & 10.691 & 10.350 & 10.556 & 9.906 \\
One-Factor & 10.322 & $\mathbf{1 0 . 1 4 5}$ & 9.963 & 9.611 & 9.278 & 8.818 \\
Two-Factor & 11.021 & $\mathbf{1 0 . 1 4 5}$ & 9.928 & 9.818 & 9.849 & $\mathbf{9 . 9 0 6}$ \\
Three-Factor & $\mathbf{5 . 0 3 6}$ & $\mathbf{1 0 . 1 4 5}$ & 10.314 & 10.243 & 10.118 & $\mathbf{9 . 9 0 6}$ \\
\hline CORR. & & & & & & \\
One-Factor & 0.571 & $\mathbf{1 . 0 0 0}$ & 0.976 & 0.960 & 0.923 & 0.901 \\
Two-Factor & 0.574 & $\mathbf{1 . 0 0 0}$ & 0.986 & 0.990 & 0.987 & $\mathbf{1 . 0 0 0}$ \\
Three-Factor & $\mathbf{1 . 0 0 0}$ & $\mathbf{1 . 0 0 0}$ & 0.986 & 0.990 & 0.987 & $\mathbf{1 . 0 0 0}$ \\
\hline CORR: corration
\end{tabular}

*CORR: correlation between fitted and observed changes. 
C. Implied Autocorrelations of Rates' Pricing Errors

Entries for exactly fitted rates are left blank.

\begin{tabular}{rllllll}
\hline & $\mathbf{3 M}$ & $\mathbf{2 Y}$ & $\mathbf{3 Y}$ & $\mathbf{5 Y}$ & $\mathbf{7 Y}$ & $\mathbf{1 0 Y}$ \\
\hline 1 week & & & & & & \\
One-Factor & 0.933 & & 0.800 & 0.910 & 0.916 & 0.954 \\
Two-Factor & 0.923 & & 0.673 & 0.689 & 0.941 & \\
Three-Factor & & & 0.620 & 0.632 & 0.946 & \\
\hline
\end{tabular}


Table 3. Out of Sample Performance Check. Observed and Fitted LIBOR and Swap Rates

The tables present the actual and implied LIBOR and swap rates. The period is from 4/7/1989 till 9/12/1997. The estimated parameters used for computations are shown in the Table 1 (the parameters are estimated using the rates' data from 2/3/1995 till 7/16/1999). The numbers in bold represent the results for exactly fitted rates (these rates are used to extract state variables, so they should be exactly the same as the corresponding market figures). We also report implied autocorrelation in the LIBOR and swap rates' pricing errors.

\section{A. Level of LIBOR and Swap Rates}

\begin{tabular}{ccccccc}
\hline & $\mathbf{3 M}$ & $\mathbf{2 Y}$ & $\mathbf{3 Y}$ & $\mathbf{5 Y}$ & $\mathbf{7 Y}$ & $\mathbf{1 0 Y}$ \\
\hline MEAN (\%) & & & & & & \\
Market & 5.734 & 6.432 & 6.734 & 7.138 & 7.379 & 7.591 \\
One-Factor & 6.212 & $\mathbf{6 . 4 3 2}$ & 6.519 & 6.677 & 6.815 & 6.987 \\
Two-Factor & 5.736 & $\mathbf{6 . 4 3 2}$ & 6.699 & 7.085 & 7.343 & $\mathbf{7 . 5 9 1}$ \\
Three-Factor & $\mathbf{5 . 7 3 4}$ & $\mathbf{6 . 4 3 2}$ & 6.715 & 7.116 & 7.369 & $\mathbf{7 . 5 9 1}$ \\
\hline STD (\%) & & & & & & \\
Market & 1.807 & 1.539 & 1.432 & 1.272 & 1.197 & 1.112 \\
One-Factor & 1.563 & $\mathbf{1 . 5 3 9}$ & 1.512 & 1.459 & 1.410 & 1.342 \\
Two-Factor & 1.873 & $\mathbf{1 . 5 3 9}$ & 1.411 & 1.257 & 1.175 & $\mathbf{1 . 1 1 2}$ \\
Three-Factor & $\mathbf{1 . 8 0 7}$ & $\mathbf{1 . 5 3 9}$ & 1.426 & 1.277 & 1.190 & $\mathbf{1 . 1 1 2}$ \\
\hline M.A.E. (bps) & & & & & & \\
One-Factor & 62.567 & $\mathbf{0 . 0 0 0}$ & 22.037 & 47.409 & 58.281 & 63.652 \\
Two-Factor & 39.524 & $\mathbf{0 . 0 0 0}$ & 4.287 & 6.368 & 4.871 & $\mathbf{0 . 0 0 0}$ \\
Three-Factor & $\mathbf{0 . 0 0 0}$ & $\mathbf{0 . 0 0 0}$ & 3.008 & 4.629 & 3.064 & $\mathbf{0 . 0 0 0}$ \\
\hline
\end{tabular}

*M.A.E: mean absolute pricing error.

\section{B. Weekly Changes of LIBOR and Swap Rates}

\begin{tabular}{cllllll}
\hline & $\mathbf{3 M}$ & $\mathbf{2 Y}$ & $\mathbf{3 Y}$ & $\mathbf{5 Y}$ & $\mathbf{7 Y}$ & $\mathbf{1 0 Y}$ \\
\hline MEAN (bps) & & & & & & \\
Market & -1.046 & -0.962 & -0.899 & -0.823 & -0.787 & -0.735 \\
One-Factor & -0.973 & $\mathbf{- 0 . 9 6 2}$ & -0.946 & -0.914 & -0.885 & -0.846 \\
Two-Factor & -1.083 & $\mathbf{- 0 . 9 6 2}$ & -0.907 & -0.829 & -0.780 & $\mathbf{- 0 . 7 3 5}$ \\
Three-Factor & $\mathbf{- 1 . 0 4 6}$ & $\mathbf{- 0 . 9 6 2}$ & -0.914 & -0.841 & -0.789 & $\mathbf{- 0 . 7 3 5}$ \\
\hline STD (bps) & & & & & & \\
Market & 11.176 & 16.272 & 15.684 & 14.772 & 13.866 & 13.157 \\
One-Factor & 16.524 & $\mathbf{1 6 . 2 7 2}$ & 15.983 & 15.428 & 14.906 & 14.194 \\
Two-Factor & 19.634 & $\mathbf{1 6 . 2 7 2}$ & 15.132 & 13.946 & 13.457 & $\mathbf{1 3 . 1 5 7}$ \\
Three-Factor & $\mathbf{1 1 . 1 7 6}$ & $\mathbf{1 6 . 2 7 2}$ & 15.734 & 14.569 & 13.828 & $\mathbf{1 3 . 1 5 7}$ \\
\hline CORR. & & & & & & \\
One-Factor & 0.955 & $\mathbf{1 . 0 0 0}$ & 0.994 & 0.964 & 0.932 & 0.899 \\
Two-Factor & 0.965 & $\mathbf{1 . 0 0 0}$ & 0.999 & 0.998 & 0.999 & $\mathbf{1 . 0 0 0}$ \\
Three-Factor & $\mathbf{1 . 0 0 0}$ & $\mathbf{1 . 0 0 0}$ & 0.999 & 0.999 & 0.999 & $\mathbf{1 . 0 0 0}$ \\
\hline CORR: cortaty
\end{tabular}

*CORR: correlation between fitted and observed changes. 
C. Implied Autocorrelations of Rates' Pricing Errors

Entries for exactly fitted rates are left blank.

\begin{tabular}{rllllll}
\hline & 3M & 2Y & 3Y & 5Y & 7Y & 10Y \\
\hline 1 week & & & & & & \\
One-Factor & 0.939 & & 0.985 & 0.992 & 0.992 & 0.992 \\
Two-Factor & 0.858 & & 0.804 & 0.862 & 0.762 & \\
Three-Factor & & & 0.729 & 0.799 & 0.657 & \\
\hline
\end{tabular}




\section{Table 4. Principal Component Analysis}

The tables show the results of standard principal component analysis of data. The 3-month LIBOR and 2-, 3-, 5-, 7-, and 10-year swap rates are from 2/3/1995 to 7/16/1999.

\section{A. Principal Component Analysis on Changes in Rates}

\begin{tabular}{lccccccc}
\hline & $\mathbf{\Delta 3 M}$ & $\boldsymbol{\Delta} \mathbf{2 Y}$ & $\boldsymbol{\Delta 3 \mathbf { Y }}$ & $\boldsymbol{\Delta 5 Y}$ & $\boldsymbol{\Delta 7 Y}$ & $\boldsymbol{\Delta} \mathbf{1 0 Y}$ & T.V.E (\%)* \\
\hline Level & 0.1228 & 0.4298 & 0.4624 & 0.4500 & 0.4542 & 0.4214 & 93.697 \\
\hline Slope & -0.8662 & -0.2727 & -0.1120 & 0.0812 & 0.2231 & 0.3262 & 3.554 \\
\hline Curvature & 0.4817 & -0.6007 & -0.2884 & -0.0351 & 0.3553 & 0.4433 & 1.961 \\
\hline Factor 4 & -0.0096 & -0.6056 & 0.6616 & 0.2352 & 0.0158 & -0.3738 & 0.327 \\
\hline
\end{tabular}

* Total Variation Explained

\section{B. R-square: Regression of Changes in Rates on Factors}

Each entry is a R-square for a regression of a rate's weekly changes of one of the factors from Table 3, Panel A. The principal component analysis factors are independent by construction.

\begin{tabular}{lccc}
\hline & $\mathbf{\Delta 3 M}$ & $\boldsymbol{\Delta 2} \mathbf{Y}$ & $\boldsymbol{\Delta 1 0 Y}$ \\
\hline On Level & 0.3178 & 0.9411 & 0.9481 \\
\hline On Slope & 0.5934 & 0.0188 & 0.0252 \\
\hline On Curvature & 0.1078 & 0.0429 & 0.0257 \\
\hline
\end{tabular}

\section{R-square: Regression of Factors on Changes in Implied State Vectors}

Each entry is a R-square for a regression of one of the principal component analysis factors on an implied state vector. Implied state vectors correspond to the estimates shown in Table 1.

\begin{tabular}{cccc}
\hline & Level & Slope & Curvature \\
\hline One-Factor & & & \\
on $\Delta y$ & 0.9402 & 0.0180 & 0.0385 \\
\hline Two-Factor & & & \\
on $\Delta y_{1}$ & 0.0047 & 0.3622 & 0.5983 \\
on $\Delta y_{2}$ & 0.7615 & 0.0981 & 0.1295 \\
on $\Delta y_{1}+\Delta y_{2}$ & 0.9934 & 0.3634 & 0.5983 \\
\hline Three-Factor & & & \\
on $\Delta y_{1}$ & 0.5517 & 0.0153 & 0.4215 \\
on $\Delta y_{2}$ & 0.6866 & 0.1061 & 0.1932 \\
on & 0.0082 & 0.2210 & 0.7339 \\
on $\Delta y_{1}+\Delta y_{2}+\Delta y_{3}$ & 0.9940 & 0.9922 & 0.9602 \\
\hline
\end{tabular}


Table 5. Prediction of 3-Month Changes of LIBOR and Swap Rates

\section{A. Sample: 3-Month Changes of Rates (bps)}

Because we work with weekly data, a 3-month period is assumed to be equal to 13 weeks. That assumption gives us 17 three-month changes for 233 weeks.

\begin{tabular}{lccc}
\hline & 3M & 2Y & 10Y \\
\hline Mean & -6.8250 & -15.7250 & -15.8813 \\
\hline STD & 24.3526 & 59.2229 & 44.9111 \\
\hline
\end{tabular}

\section{B. Prediction of 3-Month Changes}

\begin{tabular}{cccc}
\hline & const (bps) & B & R-square \\
\hline 3M LIBOR & & & \\
One-Factor & $20.1804^{*}$ & $0.6844 * *$ & 0.1330 \\
Two-Factor & $10.8231^{*}$ & $0.5693^{* *}$ & 0.0905 \\
Three-Factor & $-7.5643^{*}$ & $0.4928^{* *}$ & 0.0973 \\
\hline 2Y Swap & & & \\
One-Factor & 1.4707 & 0.0092 & 0.3773 \\
Two-Factor & $1.4086^{*}$ & 0.0397 & 0.4270 \\
Three-Factor & -7.4916 & -0.0319 & 0.0732 \\
\hline 10Y Swap & & & \\
One-Factor & $0.5563 *$ & -0.1251 & 0.0612 \\
Two-Factor & -1.4580 & 0.0224 & 0.4396 \\
Three-Factor & -2.1863 & -0.0003 & 0.0001 \\
$*$ - insignificantly different from $0, * *$ insignificantly different from 1.
\end{tabular}




\section{Table 6. Cap and Swaption Price}

The tables report means, standard deviations, and mean absolute errors (M.A.E.s) of actual and fitted caps and swaptions data series.

\section{A. Cap Price (bps)}

The 1-, 2-, 5-, and 10-year caps are from 2/17/1995 to 7/16/1999.

\begin{tabular}{rcccc}
\hline & $\mathbf{1 Y}$ & $\mathbf{2 Y}$ & $\mathbf{5 Y}$ & $\mathbf{1 0 Y}$ \\
\hline MEAN & & & & \\
Market & 19.60 & 72.92 & 284.84 & 638.20 \\
One-Factor & 21.97 & 50.68 & 185.88 & 462.69 \\
Two-Factor & 26.66 & 67.55 & 235.59 & 533.18 \\
Three-Factor & 33.95 & 88.04 & 292.94 & 618.39 \\
\hline STD & & & & \\
Market & 5.57 & 15.80 & 48.88 & 81.51 \\
One-Factor & 6.20 & 0.56 & 25.25 & 82.39 \\
Two-Factor & 5.32 & 3.97 & 13.32 & 18.82 \\
Three-Factor & 5.73 & 5.01 & 8.52 & 9.84 \\
\hline Bid/Ask & 1.70 & 5.51 & 33.01 & 54.74 \\
M.A.E & & & & \\
One-Factor & 7.24 & 23.00 & 104.61 & 204.93 \\
Two-Factor & 9.47 & 11.64 & 53.00 & 110.77 \\
Three-Factor & 15.03 & 17.36 & 36.62 & 70.59 \\
\hline
\end{tabular}

\section{B. Swaption Price (bps)}

The 3-month-2-year, 3-month-5-year, 3-month-10-year, 2-year-2-year, 2-year-5-year, and 2-year-10-year swaptions are from 2/17/1995 to 7/16/1999.

\begin{tabular}{ccccccc}
\hline & 3M2Y & 3M5Y & 3M10Y & 2Y2Y & 2Y5Y & 2Y10Y \\
\hline MEAN & & & & & & \\
Market & 37.75 & 86.97 & 144.85 & 104.57 & 228.45 & 358.50 \\
One-Factor & 32.64 & 73.48 & 92.86 & 75.78 & 174.73 & 187.16 \\
Two-Factor & 39.02 & 78.55 & 118.63 & 87.57 & 208.57 & 277.01 \\
Three-Factor & 44.03 & 85.01 & 95.56 & 104.30 & 187.97 & 322.79 \\
\hline STD & & & & & & \\
Market & 8.06 & 15.40 & 20.61 & 15.99 & 26.95 & 36.19 \\
One-Factor & 7.48 & 35.07 & 70.29 & 18.88 & 52.55 & 91.36 \\
Two-Factor & 6.73 & 18.86 & 24.43 & 7.64 & 17.65 & 32.66 \\
Three-Factor & 1.01 & 5.43 & 7.86 & 4.37 & 15.43 & 32.05 \\
\hline Bid/Ask & 3.37 & 8.12 & 14.49 & 9.17 & 21.40 & 37.40 \\
M.A.E & & & & & & \\
One-Factor & 7.92 & 25.29 & 68.08 & 28.81 & 59.00 & 171.34 \\
Two-Factor & 8.42 & 17.88 & 28.95 & 18.76 & 31.39 & 81.49 \\
Three-Factor & 8.26 & 11.68 & 49.52 & 12.50 & 42.15 & 59.10 \\
\hline
\end{tabular}




\section{Table 7. Real and Estimated Cap Prices and Slope of Yield Curve}

The tables report regression coefficients for regressions of the following form

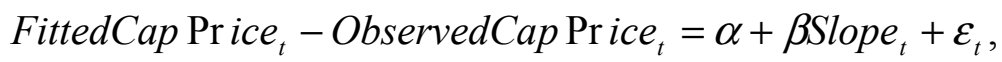

P-values for each coefficient are reported in parentheses.

\section{A. 3Month-2 Year Slope}

For this table Slope $=2$-Year Swap Rate -3-Month LIBOR Rate.

\begin{tabular}{|r|c|c|c|c|}
\hline & $\mathbf{1 Y}$ & $\mathbf{2 Y}$ & $\mathbf{5 Y}$ & $\mathbf{1 0 Y}$ \\
\hline One-Factor & 15.9752 & -9.1432 & -54.7213 & -124.2013 \\
& $(0.0000)$ & $(0.0008)$ & $(0.0000)$ & $(0.0000)$ \\
Two-Factor & 14.0395 & -5.1930 & -17.7983 & -9.2060 \\
& $(0.0000)$ & $(0.0197)$ & $(0.0075)$ & $(0.4386)$ \\
Three-Factor & 14.9764 & 3.4068 & -12.1523 & -43.7534 \\
& $(0.0000)$ & $(0.1872)$ & $(0.1071)$ & $(0.0020)$ \\
\hline
\end{tabular}

\section{B. 3Month-10Year Slope}

For this table Slope $=10$-Year Swap Rate -3 -Month LIBOR Rate.

\begin{tabular}{|c|c|c|c|c|}
\hline & $\mathbf{1 Y}$ & $\mathbf{2 Y}$ & $\mathbf{5 Y}$ & $\mathbf{1 0 Y}$ \\
\hline One-Factor & 9.4554 & -18.0537 & -98.5700 & -223.8566 \\
& $(0.0000)$ & $(0.0000)$ & $(0.0000)$ & $(0.0000)$ \\
Two-Factor & 6.7235 & -11.8317 & -38.2459 & -56.1248 \\
& $(0.0000)$ & $(0.0000)$ & $(0.0000)$ & $(0.0000)$ \\
Three-Factor & 6.7174 & -7.9676 & -40.6191 & -92.9875 \\
& $(0.0000)$ & $(0.0001)$ & $(0.0000)$ & $(0.0000)$ \\
\hline
\end{tabular}


Figure 1: LIBOR and Swap Rates

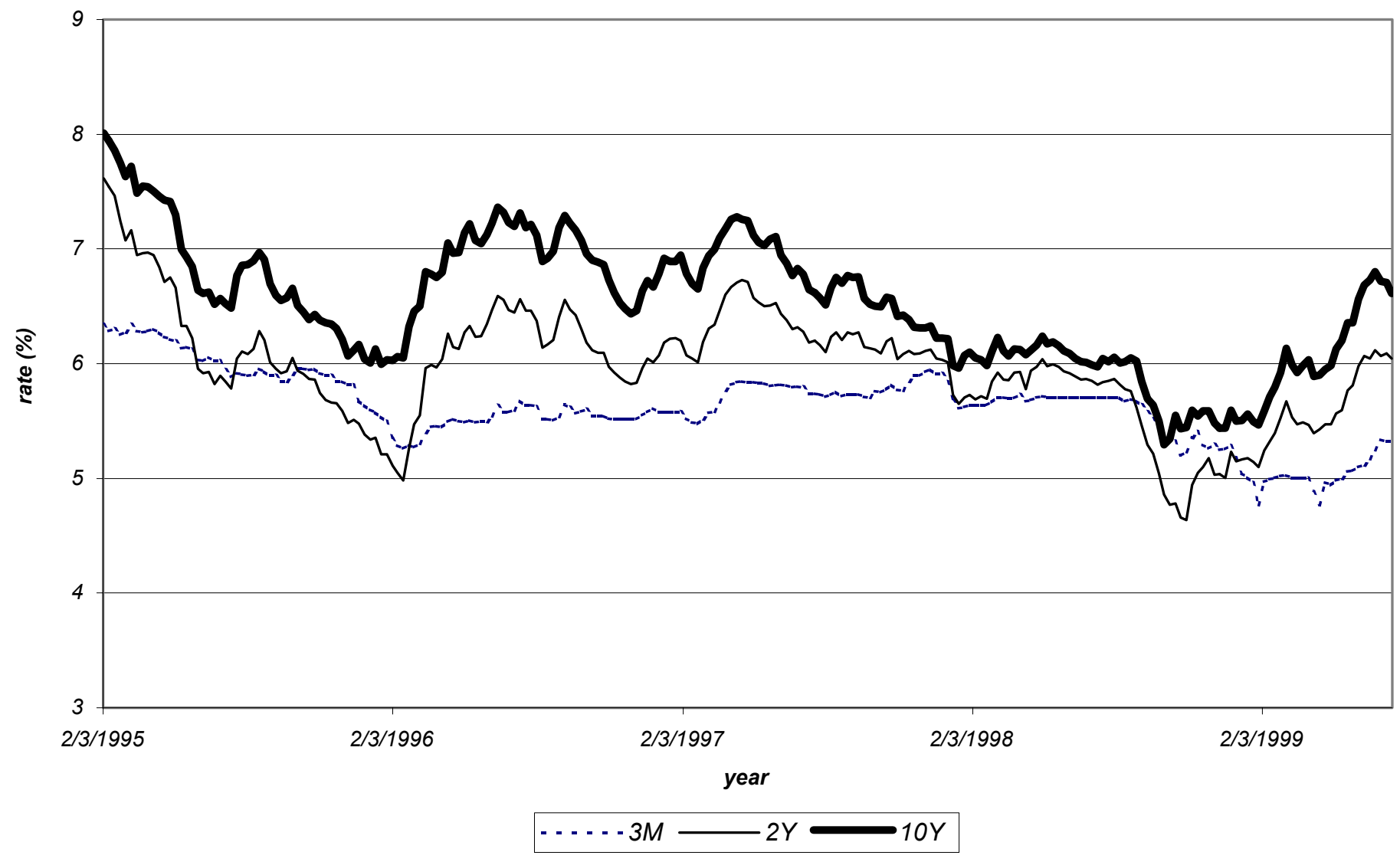


Figure 2: 3M LIBOR

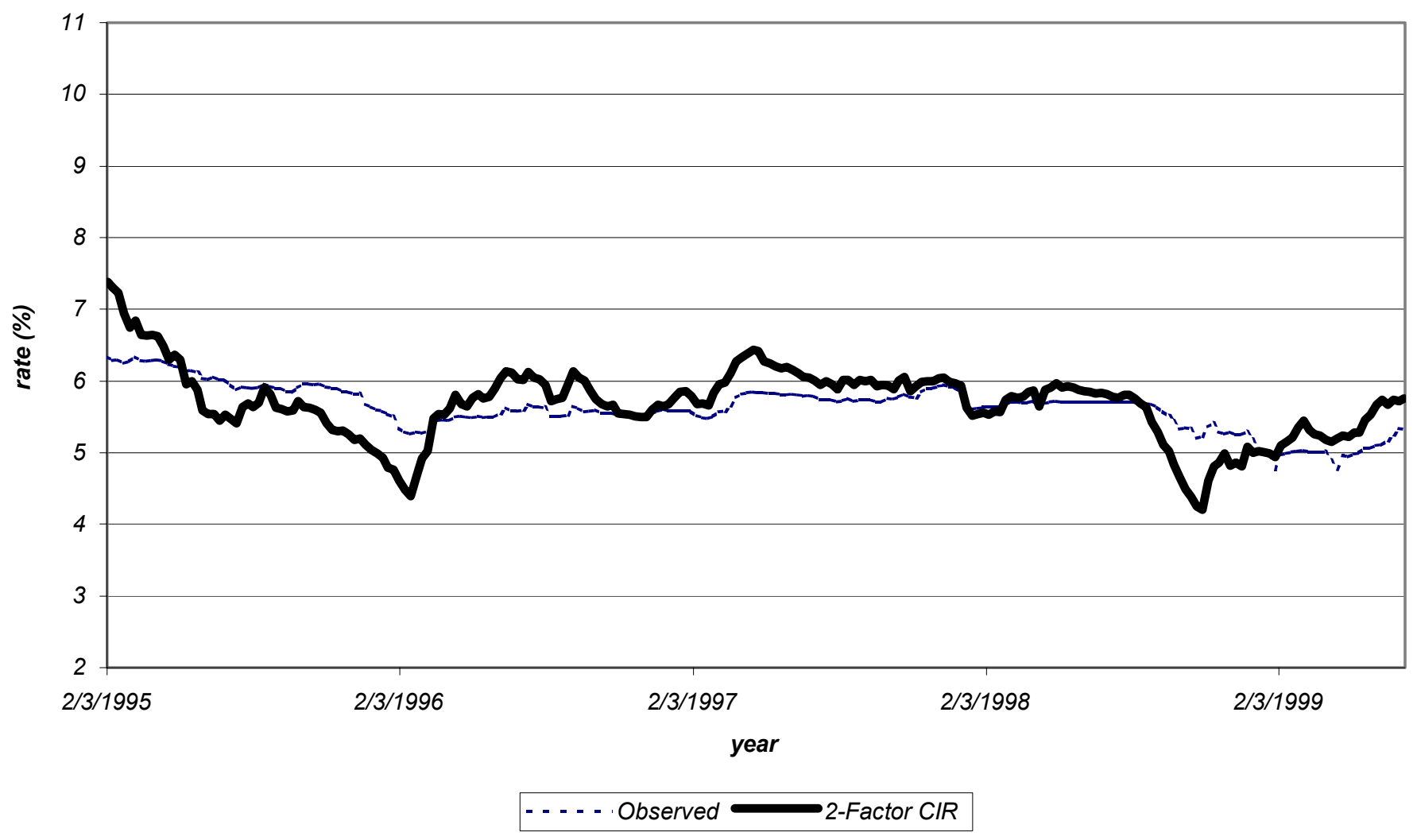


Figure 3: Weekly Changes Volatility

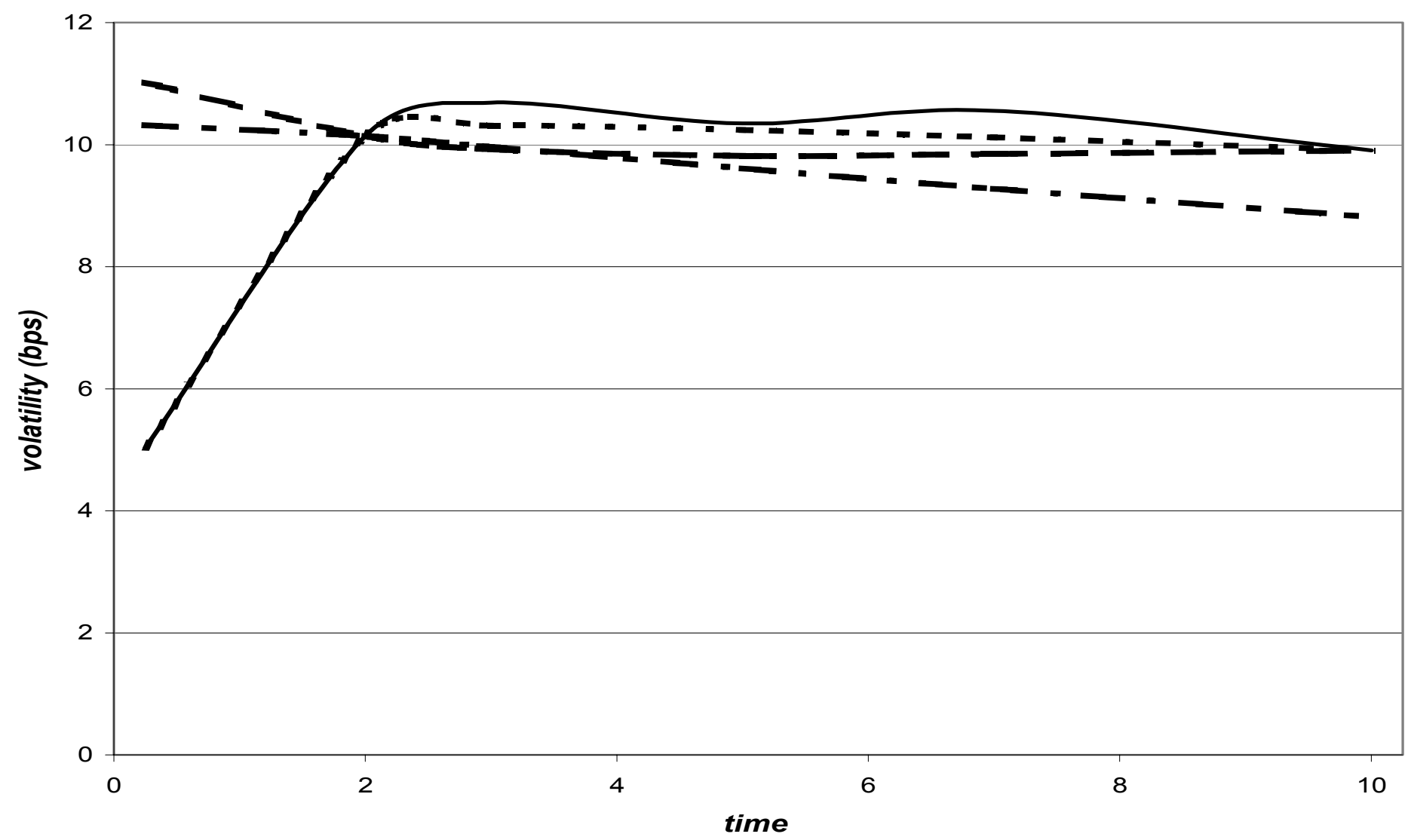

Market 1-Factor $\longrightarrow$ 2-Factor - $\quad$ 3-Factor 
Figure 4: 1Y ATM Cap

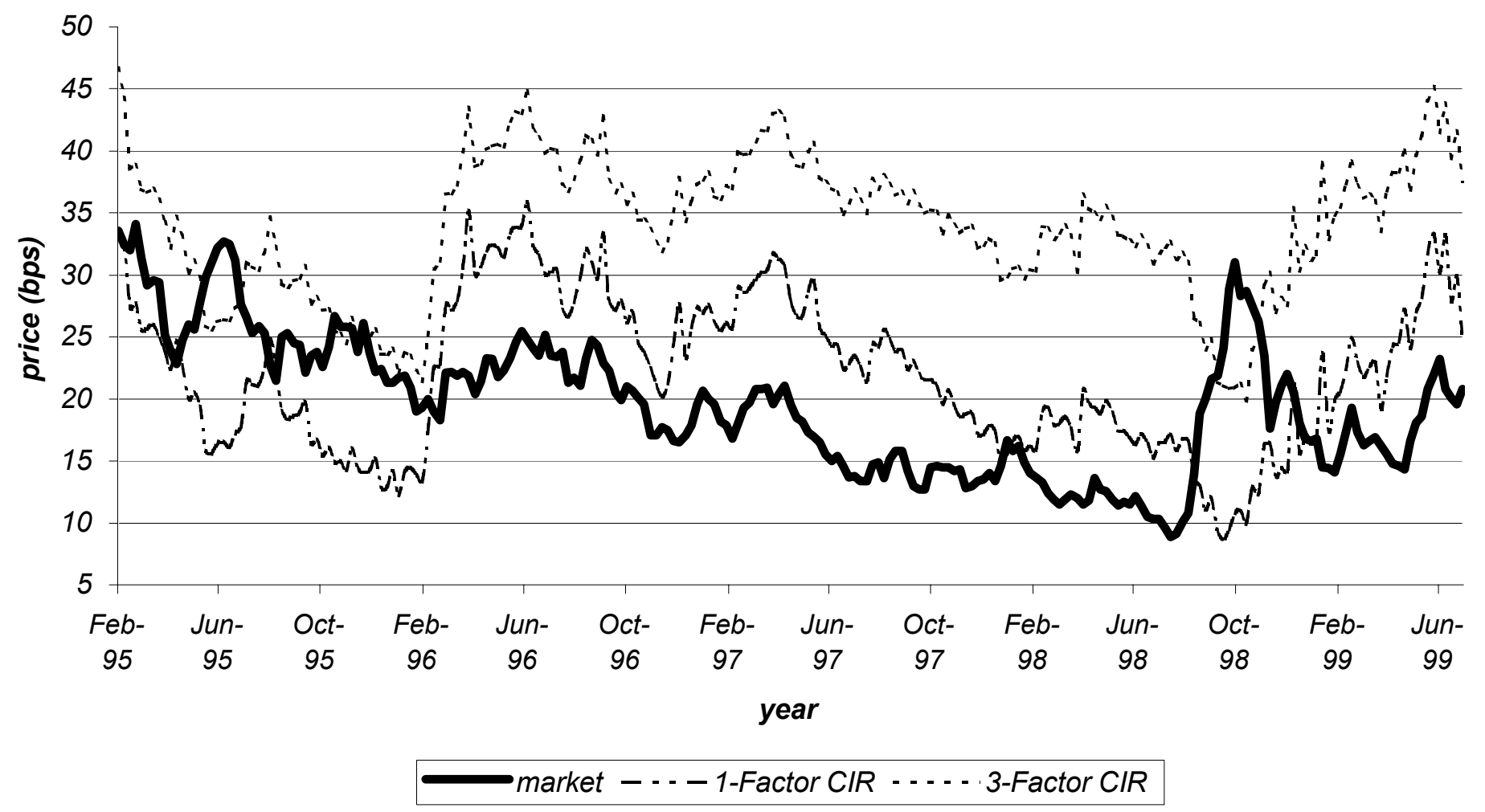


Figure 5: 3M2Y ATM Swaption

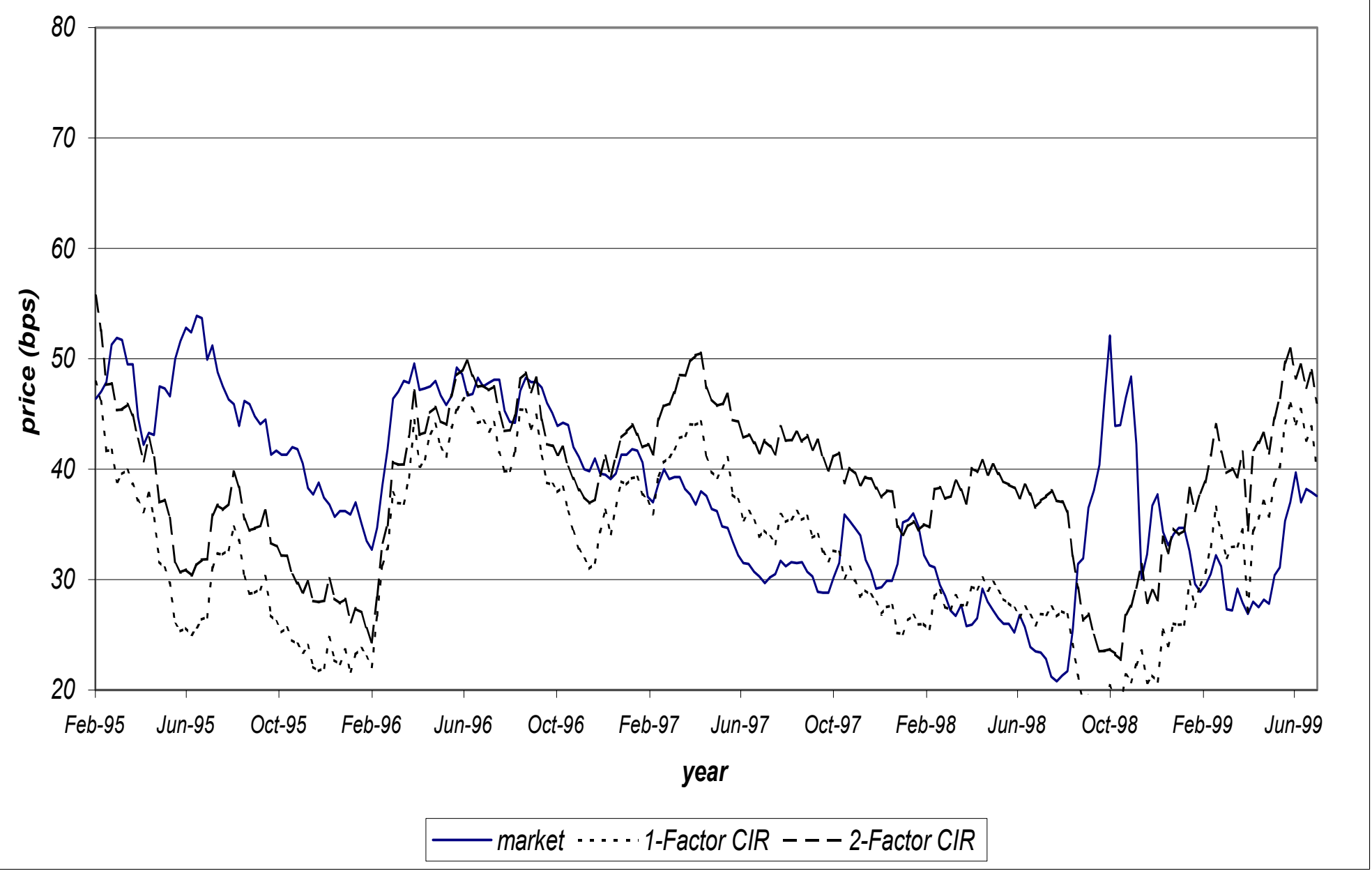




\section{References}

Aït-Sahalia, Y., 1996, "Testing Continuous-Time Models of the Spot Interest Rate," Review of Financial Studies, 9(2), 385-426.

Andersen, T. and J. Lund, 1997, "Short Rate Diffusion: Sources of Steepness, Level and Curvature in the Yield Curve," working paper, Northwestern University.

Attari, M., 1999, “Testing Interest Rate Models: What Does Futures and Options Data Tell Us?" working paper, University of Wisconsin at Madison.

Backus, D., S. Foresi, A. Mozumbar and L. Wu, 1998, "Predictable Changes in Yields and Forward Rates," NBER working paper no. 6379.

Bansal, R. and H. Zhou, 2000, "Term Structure of Interest Rates with Regime Shifts," working paper, Duke University.

Beaglehole, D. and M. Tenny, 1991, "General Solutions of Some Interest Rate Contingent Claim Pricing Equations," Journal of Fixed Income, September 1991, 69-83.

Berndt, E., B. Hall, R. Hall, and J. Hausman, 1974, "Estimation and Inference in Nonlinear Structural Models," Annals of Economic and Social Measurement, 3/4, 653-665.

Bjork, T., 1996, “Interest Rate Theory," Department of Finance, Stockholm School of Economics, Sweden. To appear in Springer Lecture Notes in Mathematics.

Black, F., 1976, "The Pricing of Commodity Contracts," Journal of Financial Economics, 3, 167-179.

Black, F., E. Derman and W. Toy, 1990, "A One-Factor Model of Interest Rates and Its Application to Treasury Bond Options," Financial Analyst Journal, JanuaryFebruary 1990, 33-39.

Black, F. and P. Karasinski, 1991, "Bond and Option Pricing when Short Rates are Lognormal,” Financial Analyst Journal, July-August 1991, 52-59.

Brennan, M. J. and E. S. Schwartz, 1979, "A Continuous-time Approach to the Pricing of Bonds," Journal of Banking and Finance, 3, 133-155.

Chacko, G. and S. Das, 2000, "Pricing Interest Rate Derivatives: A General Approach," working paper, Harvard University. 
Chan, K. C., A. Karolyi, F. Longstaff and A. Sanders, 1992, "An Empirical Comparison of Alternative Models of the Short-term Interest Rate," Journal of Finance, 48,1209-1227.

Chen, L. 1996, "Interest Rate Dynamics, Derivatives Pricing, and Risk Management," Lecture Notes in Economics and Mathematical Systems, 435, Springer.

Chen, R.-R., and L. Scott, 1992, "Pricing Interest Rate Options in a Two-Factor CoxIngersoll-Ross Model of the Term Structure," Review of Financial Studies. 5 (4), 613-636.

Chen, R.-R. and L. Scott, 1993, "Maximum Likelihood Estimation for a Multifactor Equilibrium Model of the Term Structure of Interest Rates," Journal of Fixed Income, December 1993, 14-31.

Chen, R.-R. and L. Scott, 1995, "Interest Rate Options in Multifactor Cox-Ingersoll-Ross Models of the Term Structure" Journal of Fixed Income, Winter 1995, 53-72.

Collin-Dufresne, P. and R. S. Goldstein, "Do Bonds Span Fixed Income Markets? Theory and Evidence for 'Unspanned' Stochastic Volatility," working paper, Carnegie Mellon University

Constantinides, G., 1992, "A Theory of the Nominal Term Structure of Interest Rates," Review of Financial Studies, 5(4), 531-552.

Cox, J., J. Ingersoll and S. Ross, 1985, "A Theory of the Term Structure of Interest Rates," Econometrica, 53(2), 385-407.

Das, S. and S. Foresi, 1996, "Exact Solutions for Bond and Option Prices with Systematic Jump Risk," Review of Derivatives Research, 1, 7-24.

Dai, Q. and K. Singleton, 1999, "Specification Analysis of Affine Term Structure Models," working paper, Stanford Graduate School of Business.

Dothan, M., 1978, "On the Term Structure of Interest Rates," Journal of Financial Economics, 6, 59-69.

Duarte, J., 2000, "The Relevance of the Price of Risk in Affine Term Structure Models," working paper.

Duffee, G., 2000, "Term Premia and Interest Rate Forecasts in Affine Models," working paper, Haas School of Business, UC Berkeley.

Duffie, D. and K. Singleton, 1997, "An Econometric Model of the Term Structure of Interest Rate Swap Yields," Journal of Finance, 52, 1287-1321. 
Duffie, D. and K. Singleton, 1999, "Modeling Term Structures of Defaultable Bonds," Review of Financial Studies, 12, 687-720.

Feller, W., 1951, “Two Singular Diffusion Problems," Annals of Mathematics, 54, 173182.

Friedman, A., 1975, "Stochastic Differential Equations and Application (I)," Academic Press, New York.

Ghysels, E. and S. Ng, 1998, "A Semi-Parametric Factor Model of Interest Rates and Tests of the Affine Term Structure," Review of Economics and Statistics, 80, 535548.

Grinblatt, M., 1995, "An Analytic Solution for Interest Rate Swap Spreads," working paper no. 9-94, Anderson Graduate School of Management, UCLA.

Harrison, M. and D. Kreps, 1979, "Martingales and Arbitrage in Multiperiod Security Markets," Journal of Economic Theory, 20, 381-408.

Ho, T. 1995, "Evolution of Interest Rate Models: A Comparison," Journal of Derivatives, Summer 1995, 9-20.

Hull, J., 1997, "Options, Futures and Other Derivatives," Third Edition, Prentice Hall, New Jersey.

Johannes, M., 1999, “Jumps in Interest Rates: A Nonparametric Approach,” Job Market Paper, Department of Economics, University of Chicago.

Johnson, N. and S. Kotz, 1983, "Continuous Univariate Distributions," John Wiley \& Sons.

Karlin, S. and H. Taylor, 1981, "A Second Course in Stochastic Process," Academic Press, New York.

Litterman, R. and A. Scheinkman, 1991, "Yield Curve Factors," Journal of Fixed Income, June 1991, 54-61.

Longstaff, F. and E. Schwartz, 1992, "Interest Rate Volatility and the Term Structure: A Two-Factor General Equilibrium Model," Journal of Finance, 47, 1259-1282.

Longstaff, F., P. Santa-Clara and E. Schwartz, 2000, "The Relative Valuation of Caps and Swaptions: Theory and Empirical Evidence," working paper, Anderson Graduate School of Management, UCLA.

Marsh, T. and E. Rosenfeld, 1983, "Stochastic Processes for Interest Rates and Equilibrium Bond Prices," Journal of Finance, 38, 635-646. 
Øksendal, B., 1998, "Stochastic Differential Equations: An Introduction with Applications," 5th Edition, Springer-Verlag, Berlin Heidelberg.

Pearson, N. and T. Sun., 1994, "Exploiting the Conditional Density in Estimating the Term Structure: An Application to the Cox, Ingersoll, and Ross Model," Journal of Finance, 49(4), 1279-1304.

Piazzesi, M., 1999, “An Econometric Model of the Yield Curve with Macroeconomic Jump Effects,” Job Market Paper, Department of Economics, Stanford University.

Stanton, R., 1997, “A Nonparametric Model of Term Structure Dynamics and the Market Price of Interest Rate Risk," working paper; forthcoming in Journal of Finance.

Sun, G., 1997, “The Test Function Method for Estimating Continuous-Time Models of Short Term Interest Rate," working paper, Department of Finance, University of Minnesota.

Sun, G., 1998, “Essays on Term Structure Models," unpublished dissertation, University of Minnesota.

Vasicek, O., 1977, “An Equilibrium Characterization of the Term Structure,” Journal of Financial Economics, 5, 177-188.

Wei, D. and D. Guo, 1997, "Pricing Risky Debt: An Empirical Comparison of the Longstaff and Schwartz and Merton Models," Journal of Fixed Income, September 1997, 8-28. 